\title{
Postsynaptic TrkB-Mediated Signaling Modulates Excitatory and Inhibitory Neurotransmitter Receptor Clustering at Hippocampal Synapses
}

\author{
Sarina B. Elmariah, ${ }^{1}$ Mark A. Crumling, ${ }^{2}$ Thomas D. Parsons, ${ }^{2}$ and Rita J. Balice-Gordon ${ }^{1}$ \\ ${ }^{1}$ Department of Neuroscience, University of Pennsylvania School of Medicine, and ${ }^{2}$ Department of Clinical Science, University of Pennsylvania School of \\ Veterinary Medicine, Philadelphia, Pennsylvania 19104
}

\begin{abstract}
Tyrosine receptor kinase B (TrkB)-mediated signaling modulates synaptic structure and strength in hippocampal and other neurons, but the underlying mechanisms are poorly understood. Full-length and truncated TrkB are diffusely distributed throughout the dendrites and soma of rat hippocampal neurons grown in vitro. Manipulation of TrkB-mediated signaling resulted in dramatic changes in the number and synaptic localization of postsynaptic NMDA receptor (NMDAR) and $\mathrm{GABA}_{\mathrm{A}}$ receptor $\left(\mathrm{GABA}_{\mathrm{A}} \mathrm{R}\right)$ clusters. BDNF treatment resulted in an increase in the number of NMDAR and $\mathrm{GABA}_{\mathrm{A}} \mathrm{R}$ clusters and increased the proportion of clusters apposed to presynaptic terminals. Downregulation of TrkB signaling resulted in a decrease in receptor cluster number and synaptic localization. Examination of the time course of the effects of $B D N F$ on receptor clusters showed that the increase in $G_{A B A_{A}} R$ clusters preceded the increase in NMDAR clusters by at least $12 \mathrm{hr}$. Moreover, the TrkB-mediated effects on NMDAR clusters were dependent on $\mathrm{GABA}_{\mathrm{A}} \mathrm{R}$ activation. Although TTX, $\mathrm{APV}$, and CNQX treatment had no effect, blockade of $\mathrm{GABA}_{\mathrm{A}} \mathrm{Rs}$ with bicuculline abolished the BDNF-mediated increase in NMDAR cluster number and synaptic localization. In contrast, application of exogenous GABA prevented the decrease in NMDAR clusters induced by BDNF scavenging. Together, these results suggest that TrkB-mediated signaling modulates the clustering of postsynaptic $\mathrm{GABA}_{\mathrm{A}} \mathrm{Rs}$ and that receptor activity is required for a subsequent upregulation of NMDAR clusters. Therefore, TrkB-mediated effects on postsynaptic neurotransmitter clusters may be part of a mechanism that balances inhibitory and excitatory synaptic transmission in developing neural circuits.
\end{abstract}

Key words: neurotrophin; TrkB; $\mathrm{NMDA}$ receptor; $\mathrm{GABA}_{\mathrm{A}}$ receptor; activity; synapse formation

\section{Introduction}

Neurotrophins and the family of tyrosine kinase receptors (Trk) [Nerve Growth Factor (NGF)/TrkA, Brain derived neurotrophic factor (BDNF), neurotrophin-4 (NT-4)/TrkB, NT-3/TrkC] play many roles during nervous system development, regulating neuronal survival, morphology, and synaptic connectivity (for review, see Schuman, 1999; Cohen-Cory, 2002; McAllister, 2002; Vicario-Abejon et al., 2002). In hippocampal, cortical, and cerebellar neurons, BDNF and TrkB signaling have been shown to modulate dendritic and axonal growth (Cohen-Cory and Fraser, 1995; McAllister et al., 1996, 1997), influence the development of inhibitory synapses (Rutherford et al., 1997; Marty et al., 2000; Seil and Drake-Baumann, 2000; Yamada et al., 2002), modulate long-term potentiation (LTP) (Kang and Schuman, 1995; Kang

Received June 2, 2003; revised Jan. 5, 2004; accepted Jan. 6, 2004.

This work was supported by National Institutes of Health (NIH) Grant NS/AR40763 and National Science Foundation Grant 0130822 to R.B.-G., and NIH National Research Service Award NS43821 to S.B.E. We thank Dr. L. Reichardt for an anti-TrkB antibody, Regeneron Pharmaceuticals for Trk-IgG constructs, J. Barchi, M. Maronski, C. McDonough, M. O. Scott, and H. Y. Zhou for technical assistance, and Drs. K. Boahen, M. Dichter, G. Goodhill, D. Perkel, B. Shi, and members of the Balice-Gordon laboratory for helpful discussions.

Correspondence should be addressed to Dr. Rita Balice-Gordon, Department of Neuroscience, University of Pennsylvania School of Medicine, 215 Stemmler Hall, Philadelphia, PA 19104-6074. E-mail: rbaliceg@mail.med.upenn.edu.

D0I:10.1523/JNEUROSCI.4112-03.2004

Copyright $\odot 2004$ Society for Neuroscience $\quad 0270-6474 / 04 / 242380-14 \$ 15.00 / 0$ et al., 1997), and promote quantal scaling of excitatory and inhibitory synapses in postnatal neural networks (Rutherford et al., 1997, 1998). This and other work suggest that Trk-mediated effects at synapses occur by both the retrograde and anterograde exchange of neurotrophins between presynaptic and postsynaptic cells. However, the specific mechanisms by which Trk signalingmodulates synaptic structure and function remain poorly understood.

Several lines of evidence from in vivo and in vitro experiments suggest that neurotrophins can modulate neuronal excitation and inhibition by acting presynaptically as well as postsynaptically. Acute BDNF-induced enhancement of glutamatergic synaptic transmission among hippocampal neurons has been shown to be, in part, attributable to an increase in presynaptic glutamate release (Carmignoto and Vicini, 1992; Kang and Schuman, 1996; Li et al., 1998). Postsynaptically, BDNF increases the phosphorylation and alters the conductance of NMDA receptors (NMDARs), and treatment with either NMDAR antagonists or K252a, an inhibitor of Trk tyrosine phosphorylation, abolishes BDNF-induced potentiation of synaptic transmission (Levine et al., 1996, 1998). BDNF acting via TrkB has been shown to directly induce membrane depolarization through the rapid activation of a tetrodotoxin (TTX)-insensitive sodium channel, $\mathrm{Na}_{\mathrm{V}} 1.9$ (Kafitz et al., 1999; Blum et al., 2002). At inhibitory synapses in hip- 
pocampal cultures, BDNF has been shown to decrease $\mathrm{GABA}_{\mathrm{A}}$ receptor $\left(\mathrm{GABA}_{\mathrm{A}} \mathrm{R}\right)$ clustering after $12 \mathrm{hr}$ (Brunig et al., 2001) and increase $\mathrm{GABA}_{\mathrm{A}}$ receptor subunit expression after $48 \mathrm{hr}$ of treatment (Yamada et al., 2002). In interneurons, BDNF has been shown to accelerate cell growth and increase dendritic complexity as well as presynaptic GABA release (Vicario-Abejon et al., 1998; Marty et al., 2000; Yamada et al., 2002). Consistent with these results, work on cortical synapses in dissociated cultures has shown that activity regulates the strength of inhibitory synapses, in part through BDNF-dependent modulation of $\mathrm{GABA}_{\mathrm{A}}$ channel conductance (Rutherford et al., 1997; Kilman et al., 2002). We showed previously that at cholinergic neuromuscular synapses, full-length (FL) and truncated ( $\mathrm{t}$ ) isoforms of TrkB are localized to the postsynaptic membrane in and around clusters of acetylcholine receptors (AChRs). Dominant-negative disruption of postsynaptic TrkB signaling resulted in the disassembly of existing AChR clusters in muscle fibers in vivo and in vitro (Gonzalez et al., 1999), and TrkB activation reduced agrin-induced AChR cluster formation (Wells et al., 1999). Together, these studies demonstrate that there are several mechanisms by which TrkBmediated signaling modulates presynaptic as well as postsynaptic function at central and peripheral synapses.

Here, we asked whether TrkB-mediated signaling modulates postsynaptic neurotransmitter receptor clusters at CNS synapses, using hippocampal synapses in vitro as a model system. We focused on times in vitro when both excitatory and inhibitory synapses are being formed. Our results suggest that TrkB-mediated signaling increases the number and synaptic localization of NMDAR as well as $\mathrm{GABA}_{\mathrm{A}} \mathrm{R}$ clusters, and that the TrkBmediated effects on NMDARs require $\mathrm{GABA}_{\mathrm{A}} \mathrm{R}$ activity. Thus, TrkB-mediated signaling modulates postsynaptic neurotransmitter receptor clustering as part of a mechanism that balances inhibitory and excitatory synaptic transmission in developing neural circuits.

\section{Materials and Methods}

Cell culture. Primary cell cultures were prepared as described previously (Goslin et al., 1988), with minor modifications. Briefly, hippocampi were dissected from embryonic day (E) 18 rats, dissociated in $\mathrm{Ca}^{2+}$ - and $\mathrm{Mg}^{2+}$-free HBSS containing $0.03 \%$ trypsin for $20 \mathrm{~min}$, triturated in DMEM with $10 \%$ FBS, and plated at 40,000 cells $/ \mathrm{ml}$ in Neurobasal plus B27 (Invitrogen, Grand Island, NY) on poly-lysine-coated coverslips in 12 -well plates or $35 \mathrm{~mm}$ dishes. Cells were grown at $37^{\circ} \mathrm{C}, 5 \% \mathrm{CO}_{2}, 95 \%$ humidity in defined medium that was changed weekly.

Growth factor and pharmacological treatments. Neurons were treated with 0-50 ng/ml BDNF (Upstate Biotechnology, Lake Placid, NY) or 0-2 $\mu \mathrm{g} / \mathrm{ml}$ TrkB-IgG (gift from Regeneron Pharmaceuticals, Tarrytown, NY) at 1-3 $\mathrm{d}$ in vitro (DIV) and 8-11 DIV. The time course and dose dependence of the BDNF-mediated effects on NMDAR clusters were evaluated at each age. No changes in the pattern of NMDAR immunoreactivity were observed after treatment at 1-3 DIV (Dalva et al., 2000). At 8 or 9 DIV, BDNF treatments lasting 1, 10, and $60 \mathrm{~min}$ or $6,12,24$, and $36 \mathrm{hr}$ had no effect on NMDAR clusters. Forty-eight hour treatment with 50 $\mathrm{ng} / \mathrm{ml}$ BDNF led to a consistent and dramatic increase in NMDAR and $\mathrm{GABA}_{\mathrm{A}} \mathrm{R}$ clusters and was therefore used in subsequent experiments with BDNF. All treatments were replenished after $24 \mathrm{hr}$.

Dendrite number and length were measured using interactive software (MetaMorph; Universal Imaging, Downingtown, PA) and were compared between manipulated and control cultures. Treatment with BDNF at $8 \mathrm{DIV}$ for $48 \mathrm{hr}$ produced no change in pyramidal neuron dendritic number or length [number, $8.2 \pm 0.2(40), 8.6 \pm 0.3$ (42); length, $37.2 \pm$ $1.4,36 \pm 1.8 \mu \mathrm{m}$ in BDNF-treated and untreated controls, respectively; not significantly different; Student's $t$ test]. Similarly, treatment with TrkB-IgG produced no change in dendritic number or length in pyramidal neurons [number, $9 \pm 0.4$ (35); length, $36 \pm 1.7 \mu \mathrm{m}$; not significantly different from untreated controls; Student's $t$ test]. These data are consistent with previous reports in hippocampal neurons maintained in vitro for 7-11 d or longer (Vicario-Abejon et al., 1998).

To examine effects of NT-3 or NGF, cultures were treated with different neurotrophin concentrations $(0.5-50 \mathrm{ng} / \mathrm{ml})$ and variable treatment durations ( 1 min to $48 \mathrm{hr}$ ) at 1-3 or 8-11 DIV. No effects of NT-3 or NGF on NMDAR or $\mathrm{GABA}_{\mathrm{A}} \mathrm{R}$ cluster formation or maintenance were observed (see Fig. $2 B-E$; Table 1).

For activity manipulation experiments, dilutions of APV (Sigma, St. Louis, MO), bicuculline methiodide (Sigma), CNQX (Sigma), GABA (Sigma), or TTX (Calbiochem, La Jolla, CA) were made fresh on the day of the experiment and added during delivery of neurotrophins or IgG proteins. Dose-response curves were performed for the following pharmacological agents: TTX $(0-2.0 \mu \mathrm{M})$, bicuculline $(0-50 \mu \mathrm{M})$, and GABA $(0-10 \mathrm{~mm})$. For experiments requiring selective blockade of excitatory transmission, APV $(50 \mu \mathrm{M})$ and CNQX $(10 \mu \mathrm{M})$ were used (cf. Rao and Craig, 1997; Brunig et al., 2001; Kilman et al., 2002; Wardle and Poo, 2003). All pharmacological agents were replenished after $24 \mathrm{hr}$.

Delivery of neurotrophin and Trk constructs to hippocampal neurons. Recombinant, replication-defective adenoviruses, encoding FL or truncated ( $\mathrm{t}$ ) Trks (TrkB.FL, TrkC.FL, t-TrkA, TrkB.t1, t-TrkC) and enhanced green fluorescent protein (GFP; Clontech, Palo Alto, CA), under control of the cytomegalovirus (CMV) promoter and an internal ribosomal entry site sequence (Gonzalez et al., 1999) were used to infect hippocampal neuronal cultures at 7 DIV. Adenoviruses encoding the nonbiologically active marker genes lacZ and GFP (AdCMVlacZ-gfp) or GFP alone (AdCMVgfp) served as controls for nonspecific effects of viral infection, vehicle (HBS plus 1\% glycerol; glycerol keeps the virus stable while frozen), and transgene overexpression. Infected GFP + neurons were compared with uninfected GFP- neurons from the same coverslip.

Immunostaining and confocal microscopy. In experiments in which anti-NMDAR, PSD-95 (postsynaptic density-95), and synaptophysin (SP) immunostaining were performed, hippocampal neurons were fixed and permeabilized with methanol at $-20^{\circ} \mathrm{C}$ for $10 \mathrm{~min}$. For anti$\mathrm{GABA}_{\mathrm{A}} \mathrm{R}-\beta 2 / 3$ and GAD immunostaining, neurons were fixed in $4 \%$ paraformaldehyde and $4 \%$ sucrose at room temperature for $15 \mathrm{~min}$. For all other experiments, neurons were fixed in $4 \%$ paraformaldehyde for 4 min, rinsed in Optimem (Invitrogen) with $0.2 \%$ Triton X-100, and blocked in Optimem containing $2 \%$ BSA. To examine surface TrkB expression, primary antibody diluted in Optimem with 2\% BSA was applied to neurons before fixation. Cells were subsequently fixed in $4 \%$ paraformaldehyde, permeabilized with $0.2 \%$ Triton X-100, and incubated with an anti-synaptophysin antibody. Double and triple labeling were performed with combinations of primary antibodies: antiNMDAR1 (1:500, rabbit polyclonal; Sigma), $\beta$-gal (1:200, monoclonal; Roche Products, Nutley, NJ), GABA $\mathrm{A}-\beta 2 / 3$ (1:100, monoclonal; Chemicon, Temecula, CA), GAD6 (1:50, monoclonal; Developmental Studies Hybridoma Bank, Iowa City, IA), GluR1 or GluR2/4 (1:500, monoclonal; Chemicon), hemagglutinin (1:50, chicken polyclonal; Fitzgerald Industries, Concord, MA), MAP2 (1:1000, monoclonal; gift from Dr. V. Lee, University of Pennsylvania, Philadelphia, PA), PSD-95 (1:500, monoclonal; Affinity Bioreagents, Golden, CO), synaptophysin (1:500, monoclonal; Sigma), synaptophysin (1:200, rabbit polyclonal; NeoMarkers, Fremont, CA), synaptic vesicle protein 2 (SV2) (1:50, monoclonal; Developmental Studies Hybridoma Bank), TrkB (1:50, rabbit polyclonal; Santa Cruz Biotechnology, Santa Cruz, CA), TrkB.FL (1: 100, rabbit polyclonal; gift from Dr. S. Feinstein, University of California, Santa Barbara, CA), and tau (1:1000, monoclonal; gift from Dr. V. Lee). Antibodies were visualized after staining with the appropriate FITC-, RITC- or cyanine 5-conjugated secondary antibodies (all used at 1:200; Jackson ImmunoResearch, West Grove, PA). Images were obtained using a laser-scanning confocal microscope system (Leica TCS 4D; Leica, Wetzlar, Germany). In each image, laser light levels and detector gain and offset were adjusted so that no pixel values were saturated in regions analyzed.

Western analysis. After neurotrophin manipulation, total cell lysates were harvested into Laemmli buffer from low-density hippocampal cultures at 10 DIV. After SDS-PAGE, samples were transferred to nitrocellulose membranes and probed for antibodies to NR1 (1:2000, rabbit 
Table 1. TrkB-mediated modulation of NMDAR cluster number, size, and synaptic localization

\begin{tabular}{|c|c|c|c|}
\hline Treatment & $\begin{array}{l}\text { NMDAR cluster } \\
\text { number }\end{array}$ & NMDAR cluster size $\left(\mu \mathrm{m}^{2}\right)$ & Percentage of synaptic localization \\
\hline None & $5.0 \pm 0.4(88)$ & $0.19 \pm 0.01$ & $12.9 \pm 2.7$ \\
\hline $50 \mathrm{ng} / \mathrm{ml} \mathrm{BDNF}$ & $9.4 \pm 0.7(86)^{\mathrm{a}}$ & $0.25 \pm 0.02^{\mathrm{a}}$ & $60.0 \pm 3.0^{\mathrm{a}}$ \\
\hline $2 \mu \mathrm{g} / \mathrm{ml}$ TrkB-lgG & $1.0 \pm 0.7(88)^{a, d}$ & $0.16 \pm 0.01^{\mathrm{a}}$ & $1.4 \pm 1.0^{\mathrm{a}}$ \\
\hline $50 \mathrm{ng} / \mathrm{ml} \mathrm{NGF}$ & $4.0 \pm 0.4(25)$ & $0.17 \pm 0.02$ & $18.4 \pm 4.6$ \\
\hline $50 \mathrm{ng} / \mathrm{ml} \mathrm{NT3}$ & $3.8 \pm 0.6(25)$ & $0.16 \pm 0.02$ & $20.5 \pm 4.7$ \\
\hline $2 \mu \mathrm{g} / \mathrm{ml}$ TrkC-lgG & $3.7 \pm 0.4(25)$ & $0.17 \pm 0.03$ & $21.4 \pm 6.5$ \\
\hline AdTrkB.t1 & $0.6 \pm 0.1(36)^{b}$ & $0.08 \pm 0.02^{b}$ & $0.8 \pm 0.3^{\mathrm{a}}$ \\
\hline AdTrkB.t1 plus BDNF & $5.9 \pm 0.4(35)^{d}$ & $0.21 \pm 0.03$ & n.d. \\
\hline Adt-TrkA & $6.1 \pm 0.6(35)$ & $0.18 \pm 0.02$ & n.d. \\
\hline Adt-TrkA plus BDNF & $10.2 \pm 0.9(30)^{\mathrm{a}}$ & $0.24 \pm 0.04^{\mathrm{a}}$ & n.d. \\
\hline BDNF plus $2 \mu \mathrm{M}$ TTX & $9.1 \pm 1.3(60)^{\mathrm{a}}$ & $0.23 \pm 0.02^{\mathrm{a}}$ & $54.6 \pm 6.8^{a, c}$ \\
\hline $2 \mu \mathrm{M} \mathrm{TTX}$ & $5.9 \pm 0.7(28)^{d}$ & $0.21 \pm 0.15$ & $51.4 \pm 6.9^{a, c}$ \\
\hline BDNF plus $50 \mu \mathrm{M}$ APV & $10.2 \pm 0.6(28)^{\mathrm{a}}$ & $0.22 \pm 0.02^{\mathrm{a}}$ & $51.6 \pm 2.8^{\mathrm{a}, \mathrm{c}}$ \\
\hline $50 \mu \mathrm{M}$ APV & $7.5 \pm 0.8(28)^{\mathrm{a}}$ & $0.19 \pm 0.01$ & $32.5 \pm 1.7^{\mathrm{a}}$ \\
\hline BDNF plus $10 \mu \mathrm{m}$ CNQX & $10.3 \pm 0.6(26)^{\mathrm{a}}$ & $0.20 \pm 0.01$ & $67.2 \pm 3.0^{b}$ \\
\hline $10 \mu \mathrm{M}$ CNQX & $4.2 \pm 0.2(24)$ & $0.17 \pm 0.01$ & $17.0 \pm 2.3$ \\
\hline BDNF plus $50 \mu \mathrm{m}$ bicuculline & $3.8 \pm 0.4(89)^{\mathrm{a}, \mathrm{c}}$ & $0.17 \pm 0.01^{d}$ & $11.1 \pm 2.1^{c}$ \\
\hline $50 \mu \mathrm{m}$ bicuculline & $5.9 \pm 0.7(28)^{c}$ & $0.21 \pm 0.02^{c}$ & $11.1 \pm 2.9^{c}$ \\
\hline TrkB-lgG plus $10 \mathrm{~mm}$ GABA & $5.5 \pm 0.4(59)^{\mathrm{e}}$ & $0.19 \pm 0.02^{\mathrm{e}}$ & $9.6 \pm 1.9^{\mathrm{e}}$ \\
\hline $10 \mathrm{~mm}$ GABA & $4.2 \pm 0.2(59)^{\mathrm{e}}$ & $0.19 \pm 0.02^{\mathrm{e}}$ & $8.0 \pm 1.7^{\mathrm{e}}$ \\
\hline
\end{tabular}

Values are shown as mean \pm SEM (number of cells from 3- 6 separate experiments). Cluster number was compared using Kruskal-Wallis ANOVA followed by Dunn's pairwise multiple comparison test. Distributions of cluster area were compared using a Kolmolgorov-Smirnov two-sample test, and synaptic localization values were compared using a $t$ test. n.d., Not determined.

asignificantly different from no treatment; $p<0.001$.

bignificantly different from no treatment; $p<0.0001$.

'Significantly different from $50 \mathrm{ng} / \mathrm{ml} \mathrm{BDNF;} p<0.001$.

dSignificantly different from $50 \mathrm{ng} / \mathrm{ml} \mathrm{BDNF} ; p<0.0001$.

eSignificantly different from $2 \mu \mathrm{g} / \mathrm{ml}$ TrkB-lgG; $p<0.001$.

polyclonal; Chemicon) or, as a loading control, Kv1.2 (1:5000, monoclonal; Upstate Biotechnology). AP-conjugated goat anti-rabbit or antimouse antisera (1:5000; Applied Biosystems, Foster City, CA) were used, and signals were visualized using chemiluminescence (WesternStar detection system; Applied Biosystems). Films were digitally scanned, and the signal was quantified using MetaMorph (Universal Imaging) software.

Quantification and statistical analysis. For each condition, a minimum of 6-10 neurons was examined on each of three coverslips in three to six independent experiments. Neurons used for analysis were randomly selected. Pyramidal neurons were distinguished from interneurons by pyramidal morphology and lack of anti-GAD immunoreactivity. In all experiments, the number, size, and synaptic localization of NMDARs, $\mathrm{GABA}_{\mathrm{A}} \mathrm{Rs}$, or other postsynaptic components were determined from confocal images using interactive software (MetaMorph, Universal Imaging). Confocal images of neurons were thresholded, and the number and area of individual clusters were determined. Values are presented as mean \pm SEM (number of cells).

Values for cluster number were compared using the Kruskal-Wallis nonparametric ANOVA test followed by Dunn's pairwise multiple comparison test. Cluster size values were plotted as cumulative histograms for each treatment, and distributions were compared using the Kolmolgorov-Smirnov two-sample test. To quantify synaptic localization, NMDAR or PSD-95 clusters with $>30-40 \%$ pixel overlap with synaptophysin clusters were considered synaptic. The percentage of synaptic localization in manipulated and control cultures was compared using Student's $t$ test.

Electrophysiology. Patch-clamp recordings were performed at room temperature $\left(20-25^{\circ} \mathrm{C}\right)$ on pyramidal neurons at $8-11$ DIV and 3-4 weeks in vitro. Gigaseal recordings were performed using borosilicate patch pipettes with resistances of 2-4 M $\Omega$. Cellular responses were amplified (Axopatch 200B, Axon Instruments, Foster City, CA; or EPC10, Heka Elektronik, Lambrecht/Pfalz, Germany), low-pass filtered at 2-2.9 $\mathrm{kHz}$, and sampled at $10 \mathrm{kHz}$. Coverslips were placed in a flow-through chamber driven by a peristaltic pump that allowed perfusion and washout of drugs. The bath solution contained the following (in $\mathrm{mM}$ ): 145 $\mathrm{NaCl}, 3 \mathrm{KCl}, 2 \mathrm{CaCl}_{2}, 1 \mathrm{MgCl}_{2}, 10$ HEPES, and 8 glucose, $\mathrm{pH} 7.4$ (300$310 \mathrm{mOsm}$ ). To record IPSCs in the whole-cell configuration, the bath solution contained APV $(50 \mu \mathrm{M})$ and CNQX $(10 \mu \mathrm{M})$ to block NMDA and AMPA receptor currents, respectively, and the internal pipette solution contained the following (in $\mathrm{mM}$ ): $152 \mathrm{KCl}, 1 \mathrm{CaCl}_{2}, 4 \mathrm{Mg}$-ATP, 1 EGTA, 10 HEPES, and 30 glucose, pH 7.4 (290-305 mOsm). To record EPSCs, the bath solution contained bicuculline $(50 \mu \mathrm{M})$ to block $\mathrm{GABA}_{\mathrm{A}} \mathrm{R}$ currents and gluconate substituted for $\mathrm{Cl}^{-}$in the internal pipette solution (in $\mathrm{mm}$ ): 130 potassium gluconate and $10 \mathrm{KCl}, \mathrm{pH} 7.4$ (290-305 mOsm). Membrane potential was held at $-70 \mathrm{mV}$.

To detect spontaneous action potential activity with minimal cellular perturbation, action currents were recorded in the cell-attached configuration. The patch pipette contained bath solution (without drugs) and was voltage clamped at $0 \mathrm{mV}$ after achieving a gigaseal. In the resulting records, current flowing into the patch pipette is plotted as a negative deflection (see Fig. 7A).

To evaluate whether functional $\mathrm{GABA}_{\mathrm{A}}$ and NMDA receptors were expressed at 8-11 DIV and to validate the effects of pharmacological agents used in the morphological studies, neurotransmitters were focally applied to neuron somata in the presence and absence of receptor antagonists. Application of GABA (5-100 $\mu \mathrm{M})$ evoked currents that were reversibly blocked by $50 \mu \mathrm{M}$ bicuculline (see Fig. $7 D$ ). In bath solution containing $10 \mu \mathrm{M}$ CNQX, application of glutamate (5-100 $\mu \mathrm{M})$ evoked NMDAR-mediated currents that were attenuated by $50 \mu \mathrm{M}$ APV (data not shown) (cf. Brunig et al., 2001; Kilman et al., 2002). In addition, $1 \mu \mathrm{M}$ TTX reversibly abolished action potentials evoked under current clamp (see Fig. 7B).

To determine whether GABA was excitatory or inhibitory, perforated patch recordings with gramicidin $\mathrm{D}$ were performed to determine the $\mathrm{GABA}_{\mathrm{A}}$ reversal potential at 4 and 8-11 DIV. Patch pipettes were tipfilled with internal solution without gramicidin and then backfilled with internal solution containing gramicidin $(20 \mu \mathrm{g} / \mathrm{ml})$. The internal pipette solution contained the following (in mM): $154 \mathrm{KCl}, 9 \mathrm{NaCl}, 1 \mathrm{MgCl}_{2}, 0.2$ EGTA, and 10 HEPES, pH 7.4 (290-305 mOsm). The bath contained 50 $\mu \mathrm{M}$ APV, $10 \mu \mathrm{M}$ CNQX, and $25 \mu \mathrm{M}$ saclofen, a GABA $\mathrm{B}_{\mathrm{B}}$ receptor antagonist. To minimize voltage errors induced by high series resistance, recordings were performed in current-clamp configuration, and only those recordings with series resistances $<100 \mathrm{M} \Omega$ were included in the analysis (mean series resistance, $63.2 \pm 5.6 \mathrm{M} \Omega ; n=20)$. GABA $(100 \mu \mathrm{M})$ was 

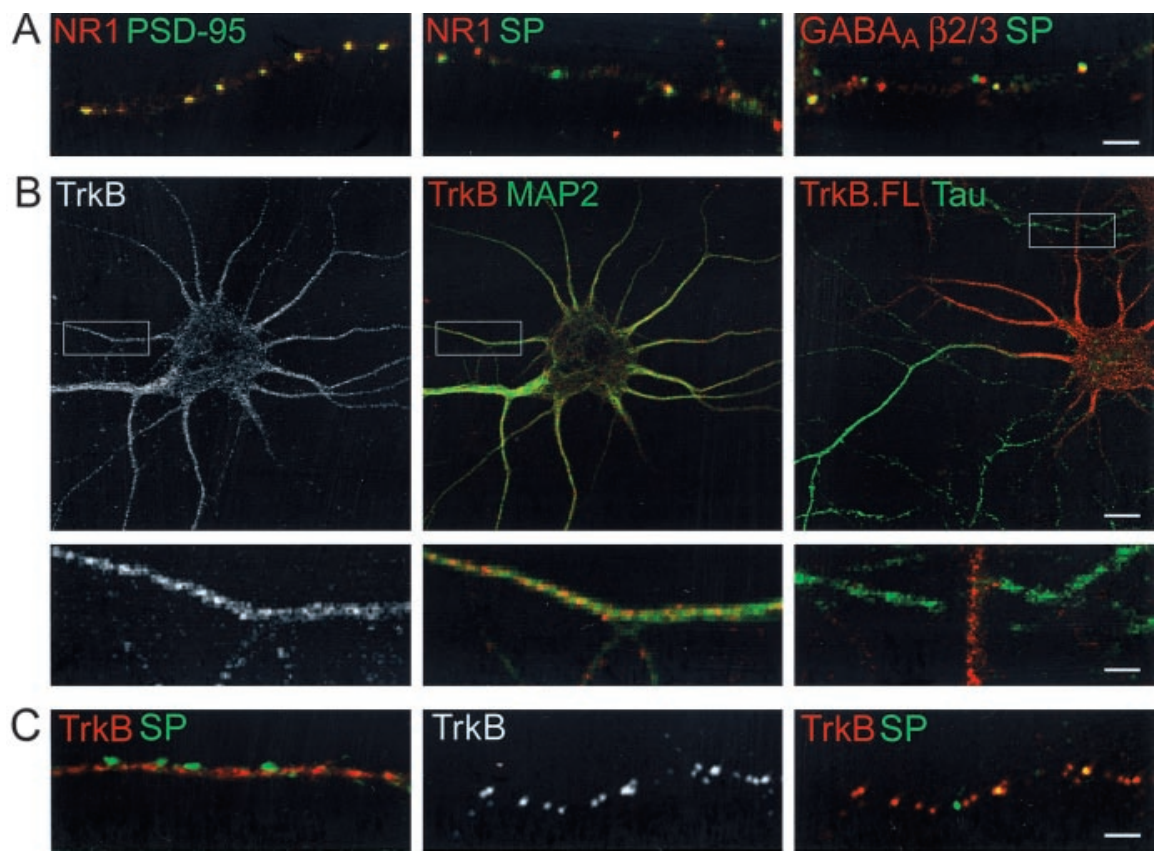

Figure 1. Localization of neurotransmitter receptor clusters and TrkB in hippocampal neurons in vitro. Hippocampal neurons at 10 DIV were immunostained and analyzed with confocal microscopy. A, Immunostaining with an antibody against NR1 (red) shows that the majority of NMDAR clusters in the dendrites of pyramidal neurons are colocalized with PSD-95 (green), a molecule that is localized to postsynaptic specializations (left), whereas few NMDAR clusters are localized to synapses, as visualized with an antibody against SP (green), a molecule localized to synaptic vesicles (middle). Immunostaining for the $G_{A B A_{A}} R$ subunit $\beta 2 / 3$ (red) shows that $\mathrm{GABA}_{A} \mathrm{R}$ clusters are present, and approximately one-third are apposed to SP-positive terminals (green) at this age (right). Scale bar, $2 \mu \mathrm{m}$. $B$, Immunostaining with an antibody against all isoforms of TrkB shows diffuse and clustered TrkB (left) distributed throughout the cell body and dendritic processes of hippocampal pyramidal neurons visualized with an antibody against MAP2 (green, middle). Full-length TrkB (red) is similarly distributed (right). Little if any TrkB is detected in axonal processes, visualized with an antibody against tau (green). Scale bar, $10 \mu \mathrm{m}$. Panels below show areas within white boxes at higher magnification. Scale bar, $2 \mu \mathrm{m}$. C, Immunostaining in permeabilized neurons with an antibody against all isoforms of TrkB (red, left) and SP (green, left) shows that TrkB is distributed diffusely throughout dendrites, with some clustered near or at synapses. Immunostaining in nonpermeabilized neurons shows that TrkB (middle) is clustered in the cell membrane. Neurons were subsequently permeabilized and immunostained with an antibody against SP (green, right) to reveal presynaptic terminals. Surface TrkB (red, right) is clustered at some synapses. Scale bar, $2 \mu \mathrm{m}$. amined cultures during the highly dynamic period of synaptogenesis, which occurs between the first and second weeks in vitro.

During this time period in vitro, immunostaining using an antibody against all TrkB isoforms showed that the receptor is expressed in all hippocampal neurons, present both diffusely and in clusters, and differentially distributed among dendrites and axons. Double labeling using antibodies against TrkB and the dendritic microtubule associated protein MAP2 showed that TrkB is distributed diffusely in somata and dendrites, with some TrkB clustered in the dendritic and somatic membrane (Fig. 1B). TrkB was also localized to the proximal portions of some axons, visualized using an antibody against tau, but was largely absent from growth cones and distal axon compartments (Fig. $1 B$ ). A similar localization was observed using antibodies specific to fulllength TrkB containing the intracellular tyrosine kinase domain (Fig. $1 B$ ). In these cultures, similar distributions were observed in hippocampal neurons with pyramidal morphology as well as in GAD + interneurons. As reported previously (Muragaki et al., 1995; Du et al., 2000; Xu et al., 2000), immunostaining for surface $\operatorname{TrkB}$ receptors and synaptophysin showed that $\operatorname{TrkB}$ was clustered in the membrane and present at some synapses; however, it was not clustered exclusively or primarily at synapses (Fig. 1C). Together, these results show that during synapse formation and maturation in vitro, TrkB is primarily localized to postsynaptic dendritic compartments, although not exclusively localized at synapses. focally applied while the cell was at rest or during one of two steady-state current commands. The amplitudes of the GABAergic responses were measured, plotted versus the initial membrane potential, and fitted via linear regression. The $y$-intercept of this line was defined as the $\mathrm{GABA}_{\mathrm{A}}$ reversal potential. The measured membrane potentials were corrected by subtracting a calculated liquid junction potential of $3.7 \mathrm{mV}$.

\section{Results}

\section{TrkB localization in hippocampal neurons in vitro}

To study the effects of neurotrophin signaling on neurotransmitter receptor cluster formation and maintenance, we first characterized the distribution of NMDARs and $\mathrm{GABA}_{\mathrm{A}} \mathrm{Rs}$ in lowdensity embryonic rat hippocampal neuronal cultures maintained in defined medium for 3-4 weeks. Immunostaining showed that NMDAR and $\mathrm{GABA}_{\mathrm{A}} \mathrm{R}$ clusters gradually increase in number and become localized to postsynaptic densities and synaptic sites during the first 3 weeks in vitro, consistent with previous reports (Rao and Craig, 1997; Brunig et al., 2001). By 7-10 DIV, $\sim 10-15 \%$ of NMDAR clusters and $35-40 \%$ of $\mathrm{GABA}_{\mathrm{A}} \mathrm{R}$ clusters were apposed to presynaptic terminals immunostained with antibodies against SP or SV2 (Fig. 1A). By the end of the second week in vitro, approximately one-third of NMDAR clusters and approximately two-thirds of $\mathrm{GABA}_{\mathrm{A}} \mathrm{R}$ clusters were synaptically localized. Thus, to determine whether TrkB signaling plays a role in the clustering or maintenance of neurotransmitter receptors, we ex-

\section{TrkB signaling modulates the number and synaptic} localization of NMDAR clusters

We first examined the effects of TrkB-mediated signaling on NMDAR clusters in cultures treated at 8-10 DIV with BDNF for $48 \mathrm{hr}$. BDNF treatment increased the number, size, and synaptic localization of NMDAR clusters in a dose-dependent manner (Fig. 2). A comparison of the number of NMDAR clusters in randomly selected pyramidal neurons from control and BDNFtreated cultures showed that NMDAR cluster density increased nearly twofold, from a mean of $5.0 \pm 0.4$ clusters per $20 \mu \mathrm{m}$ dendritic segment in untreated neurons to $9.4 \pm 0.7$ clusters per segment in neurons treated with $50 \mathrm{ng} / \mathrm{ml}$ BDNF (Fig. 2 B, Table 1). After $48 \mathrm{hr}$ of BDNF treatment, the size of NMDAR clusters was also increased $\sim 25 \%$ (Fig. $2 C$, Table 1). Increases in cluster density and size were similar across proximal and distal portions of the dendritic arbor and were observed to a lesser degree in the soma.

In addition to effects on cluster number and size, BDNF treatment also affected the localization of NMDAR clusters with other synaptic components. After BDNF treatment, a significantly higher proportion of NMDAR clusters was apposed to SP-labeled presynaptic terminals (Fig. $2 D, E$; Table 1 ) and thus synaptically localized. Surprisingly, no change in the number of SP-stained terminals was observed after BDNF treatment $[5.6 \pm 0.3$ per 20 $\mu \mathrm{m}$ dendritic segment (86 neurons); $4.9 \pm 0.7$ in untreated neu- 


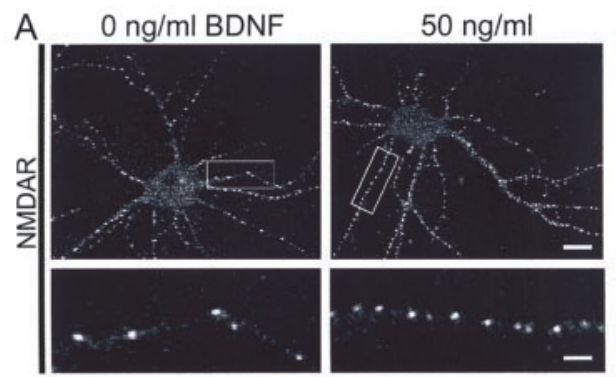

B
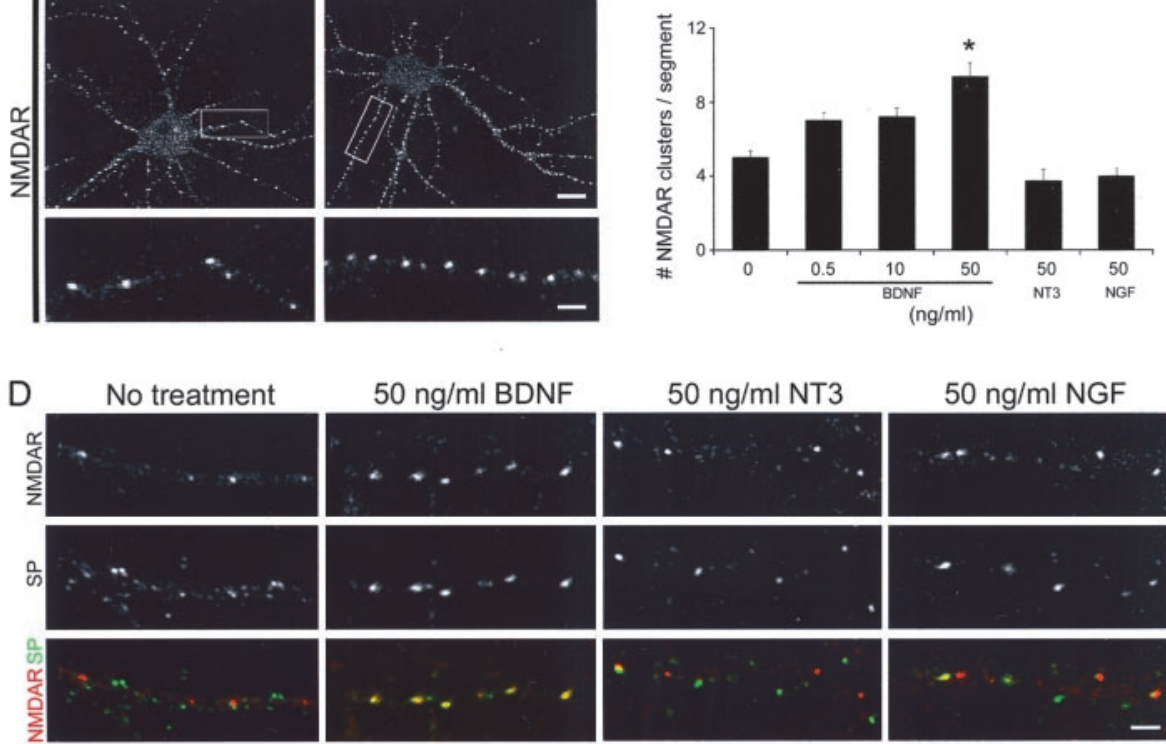

G

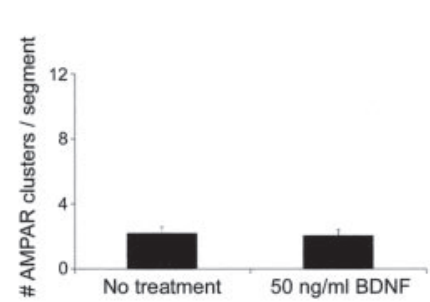

C

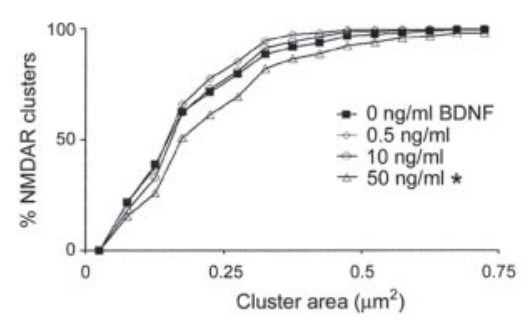

$\mathrm{E}$

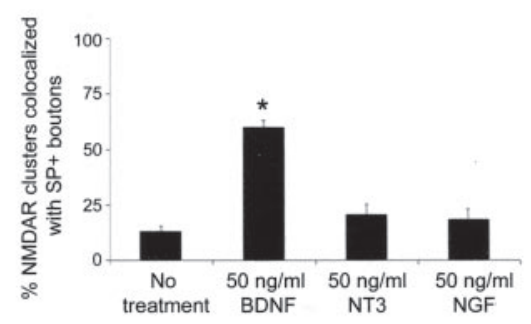

$\mathrm{H}$

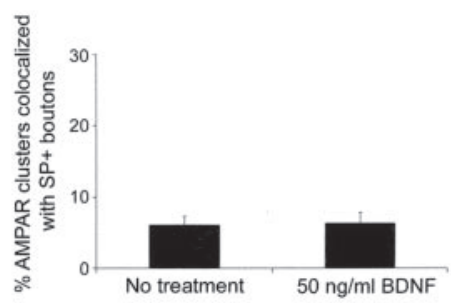

Figure 2. BDNF increases the number, size, and synaptic localization of NMDAR clusters in hippocampal neurons. Hippocampal neurons at 8 DIV were treated with $0.5-50 \mathrm{ng} / \mathrm{ml}$ BDNF for $48 \mathrm{hr}$ and were immunostained at $10 \mathrm{DIV}$ with an antibody against NR1 and SP. A, Treatment with $50 \mathrm{ng} / \mathrm{ml} \mathrm{BDNF}$ (right) leads to an increase in the number of NMDAR clusters compared with untreated control neurons (left). Scale bar, $10 \mu \mathrm{m}$. Areas within white boxes are shown below at higher magnification. Scale bar, $2 \mu \mathrm{m}$. B, Quantification of dose-dependent BDNF-mediated increase in NMDAR clusters per $20 \mu \mathrm{m}$ dendrite segment. Asterisk indicates significant increase compared with no treatment (Table 1). C, Quantification of dose-dependent BDNF-mediated increase in NMDAR cluster size. Cumulative histograms of NMDAR cluster size for each treatment are shown. Asterisk indicates significant increase compared with no treatment (Table 1). D, Treatment with $50 \mathrm{ng} / \mathrm{ml}$ BDNF (middle left) leads to an increase in the synaptic localization of NMDAR clusters compared with untreated control neurons (left). No changes in NMDAR number or synaptic localization were observed after treatment with NT-3 (middle, right) or NGF (right). Top, NMDAR clusters visualized with antibody against NR1. Middle, Presynaptic terminals visualized with an antibody against SP. Bottom, Overlay of NMDAR (red) and SP (green). Scale bar, $2 \mu \mathrm{m}$. E, Quantification of BDNF-mediated increase in synaptic localization of NMDAR clusters. Asterisk indicates significant increase compared with no treatment (Table 1). F, AMPARs are distributed diffusely in the dendrites of pyramidal neurons; few AMPAR clusters are present (arrowhead), and none are synaptically localized. Treatment with $50 \mathrm{ng} / \mathrm{ml} \mathrm{BDNF}$ (right) does not alter AMPAR cluster number or synaptic localization compared with no treatment (left). Top, AMPAR clusters were visualized with an antibody against GluR1. Middle, Presynaptic terminals with an antibody against SP. Bottom, Overlay of GluR1 (red) and SP (green). Scale bar, $2 \mu \mathrm{m}$. G, Quantification of the number of AMPAR clusters in BDNF-treated and control neurons. No significant differences were observed between BDNF-treated and control neurons. H, Quantification of synaptic localization of AMPAR clusters. No significant differences were observed between BDNF-treated and control neurons.

rons (88); not significantly different; Student's $t$ test]. This finding indicates that the increase in synaptic NMDAR clusters was not simply attributable to an increase in presynaptic boutons and thus synapses. Rather, this observation suggests that BDNF induces a dynamic change in the localization of NMDAR clusters, increasing the number of NMDARs apposed to presynaptic terminals. In contrast, the number of postsynaptic densities, labeled using an antibody against PSD-95, increased $\sim 1.3$-fold after chronic treatment with BDNF $[8.5 \pm 0.5$ per $20 \mu \mathrm{m}$ dendritic segment (86); $6.4 \pm 0.4$ in untreated neurons (88); $p<0.001$; Student's $t$ test]. However, the proportion of NMDAR clusters colocalized with PSD-95 remained unchanged [74.1 \pm 2.3 per 20 $\mu \mathrm{m}$ dendritic segment (86); $71.8 \pm 1.9$ in untreated neurons (88); not significantly different; Student's $t$ test]. These data show that TrkB-mediated signaling promotes NMDAR clustering at synapses during development in vitro. To test whether BDNFmediated modulation of postsynaptic glutamate receptors was specific for NMDA-type glutamate receptors, we examined the effects of BDNF on AMPA receptor (AMPAR) cluster formation and maintenance.

Immunostaining at 8-10 DIV for AMPA receptor subunits GluR1 and GluR2 showed that AMPARs were diffusely distributed in dendrites, with few AMPAR clusters formed at this stage of development (Fig. 2 F). In contrast to the robust upregulation of NMDAR clusters, no changes were observed in the number or synaptic localization of AMPAR clusters after treatment with BDNF (Fig. $2 \mathrm{~F}-\mathrm{H}$ ), suggesting that BDNF specifically modulates NMDAR clusters at excitatory synapses.

To determine whether the effect of BDNF on NMDAR cluster number, size, and synaptic localization are specific to TrkB signaling, the effects of TrkC or TrkA activation were examined in parallel experiments. TrkC, which binds the neurotrophin NT-3 with high affinity, is expressed in hippocampal neurons in vitro and in vivo, but little TrkA is expressed (Martinez et al., 1998). 
A

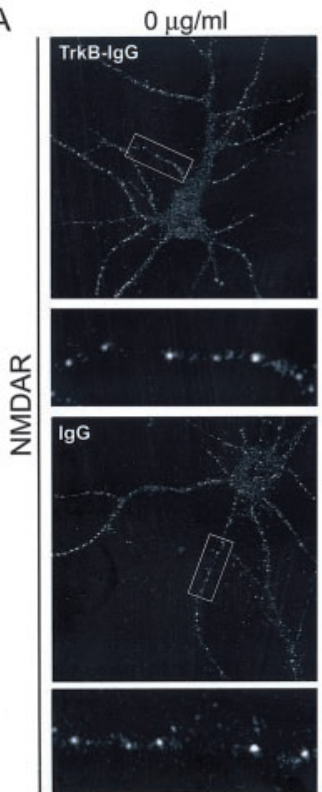

D

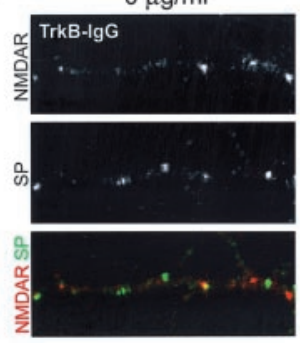

$2.0 \mu \mathrm{g} / \mathrm{ml}$
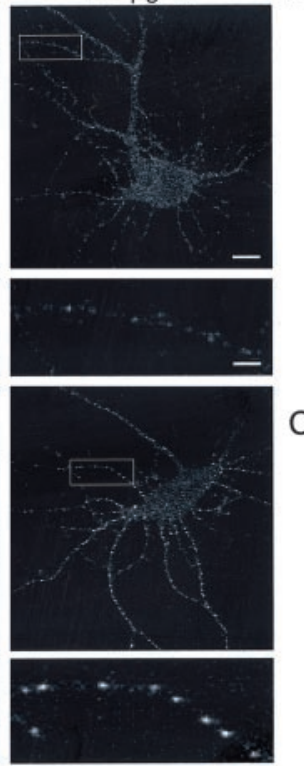

$2.0 \mu \mathrm{g} / \mathrm{ml}$

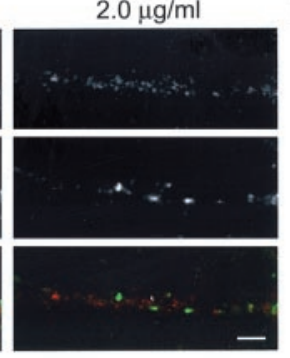

B

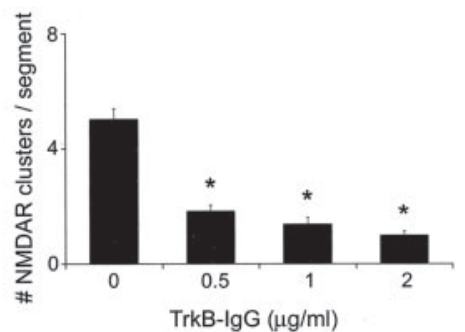

C

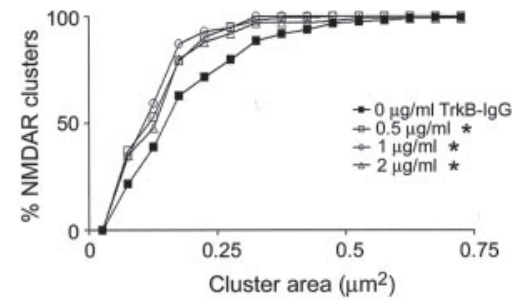

E

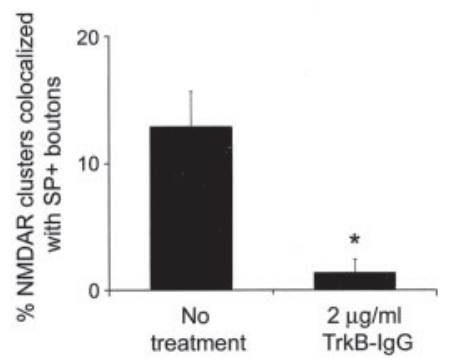

Figure 3. Scavenging endogenous BDNF decreases the number, size, and synaptic localization of NMDAR clusters in hippocampal neurons. Hippocampal neurons at 8 DIV were treated with $0.5-2.0 \mu \mathrm{g} / \mathrm{ml}$ of TrkB-lgG or control lgG for $48 \mathrm{hr}$ and were analyzed after immunostaining at $10 \mathrm{DIV}$ with an antibody against NR1 and SP. A, Treatment with $2.0 \mu \mathrm{g} / \mathrm{ml} \mathrm{TrkB}-\mathrm{lg} \mathrm{G}$ (top) leads to a decrease in the number of NMDAR clusters compared with neurons treated with lgG (bottom). Scale bar, $10 \mu \mathrm{m}$. Areas within white boxes are shown below at higher magnification. Scale bar, $2 \mu \mathrm{m}$. B, Quantification of TrkB-IgG dose-dependent decrease in NMDAR clusters per $20 \mu \mathrm{m}$ dendrite segment. Asterisk indicates significant decrease compared with no treatment (Table 1). $C$, Quantification of TrkB-lgG dose-dependent decrease in NMDAR cluster size. Cumulative histograms of NMDAR cluster size for each treatment are shown. Asterisk indicates significant decrease compared with no treatment (Table 1).D, Treatment with $2 \mu \mathrm{g} / \mathrm{ml}$ TrkB-lgG (right) leads to a decrease in the synaptic localization of intact NMDAR clusters compared with untreated control neurons (left). Top, NMDAR clusters visualized with antibody against NR1. Middle, Presynaptic terminals visualized with an antibody againstSP. Bottom, Overlay of NMDAR (red) and SP (green). Scale bar, $2 \mu \mathrm{m}$. E, Quantification of TrkB-lgG-induced decrease in the synaptic localization of NMDAR clusters compared with untreated control neurons. Asterisk indicates significant decrease compared with no treatment (Table 1).

Hippocampal neurons were treated with NT-3 or NGF at 8-10 DIV for $1 \mathrm{~min}$ to $48 \mathrm{hr}$, and NMDAR clusters were examined after immunostaining. No changes were observed in the number or synaptic localization of NMDAR clusters after treatment with NT-3 or NGF (Fig. 2B,D,E; Table 1). These results demonstrate that the BDNF-dependent modulation of NMDAR clusters is mediated specifically by TrkB signaling.

To determine whether TrkB-mediated modulation of NMDAR clusters persists in older cultures after synapses have been formed, cultures were treated at 15-17 and 22-24 DIV with BDNF for $48 \mathrm{hr}$. BDNF treatment at both 2 and 3 weeks in vitro induced an increase in NMDAR cluster number [10.6 \pm 0.5 per $20 \mu \mathrm{m}$ dendritic segment (63); $5.9 \pm 0.7$ in untreated neurons (50); $p<0.001$; Student's $t$ test] and synaptic localization [71.8 \pm 2.3 per $20 \mu \mathrm{m}$ dendritic segment (63); $32.5 \pm 5.0$ in untreated neurons (50); $p<0.001$; Student's $t$ test] similar to that observed at 1 week in vitro. Moreover, no changes were observed in NMDAR clusters after treatment with NT-3 in cultures examined

after 2-3 weeks in vitro [6.4 \pm 0.7 clusters per $20 \mu \mathrm{m}$ dendritic segment; $25.0 \pm 4.3 \%$ synaptic localization (37)]. Together, these results demonstrate that TrkB signaling modulates NMDAR cluster number and synaptic localization during at least the first 3 weeks in vitro. In subsequent experiments, we focused on TrkBmediated signaling during synaptogenesis between 8 and 10 DIV when the effects of BDNF on neurotransmitter cluster number and synaptic localization first become apparent.

\section{Postsynaptic TrkB signaling is necessary} for NMDAR cluster maintenance

To determine whether TrkB signaling is necessary for the maintenance of NMDAR clusters at hippocampal synapses, levels of endogenous BDNF were reduced by adding a TrkB-IgG fusion protein to the culture medium. This protein binds and sequesters neurotrophin, preventing its binding to and activation of surface TrkB receptors (cf. Binder et al., 1999). Hippocampal neurons at 8-10 DIV were treated for $48 \mathrm{hr}$ with $0.5-2.0 \mu \mathrm{g} / \mathrm{ml}$ of TrkB-IgG or control IgG and NMDAR clusters were analyzed after immunostaining. Scavenging endogenous BDNF resulted in a robust decrease in the number and size of NMDAR clusters in a dosedependent manner. TrkB-IgG treatment led to a fivefold reduction in the number of NMDAR clusters (Fig. 3A,B; Table 1). NMDAR cluster size also decreased significantly after treatment with TrkB-IgG in a dose-dependent manner ( 25\%) (Fig. $3 C$, Table 1). No changes were observed in the number or size of NMDAR clusters after scavenging of NT-3 with TrkC-IgG (Table 1). Therefore, TrkB ligands such as $\mathrm{BDNF}$ are necessary for the maintenance of NMDAR clusters.

In addition, NMDAR cluster localization with other synaptic components was altered by scavenging BDNF. Although the number of SP-stained presynaptic terminals observed remained unchanged after TrkB-IgG treatment compared with untreated neurons [ $4.9 \pm 0.3$ (88), $4.9 \pm 0.7$ (88), respectively; not significantly different; Student's $t$ test], a smaller proportion of NMDAR clusters was apposed to presynaptic terminals (Fig. $3 D, E$; Table 1). No change was observed in the number of PSD-95 clusters per dendritic segment after TrkB-IgG treatment compared with untreated neurons $[6.2 \pm 0.4$ (88), $6.4 \pm 0.4$ (88), respectively; not significantly different; Student's $t$ test]. However, of the few NMDAR clusters present after scavenging, $>95 \%$ remained associated with PSD-95. In addition, no changes were observed in the number or synaptic localization of AMPAR clusters per dendritic segment after TrkB-IgG treatment compared with untreated neurons [1.9 \pm 0.5 (76), $2.2 \pm 0.4$ (91), respectively; not significantly different; Student's $t$ test]. These results suggest that in the absence of BDNF, NMDARs are selec- 
tively dispersed from clusters and removed from postsynaptic sites.

At neuromuscular synapses, postsynaptic TrkB signaling is required to maintain AChR clusters in muscle fiber membranes (Gonzalez et al., 1999). While scavenging BDNF confirmed that TrkBmediated signaling is necessary for maintaining NMDAR clusters at hippocampal synapses, whether signaling was required postsynaptically could not be directly evaluated. To determine whether postsynaptic TrkB-mediated signaling is necessary for the maintenance of NMDAR clusters, endogenous TrkB signaling was downregulated in individual neurons using adenovirus-mediated overexpression of a truncated TrkB (TrkB.t1 ha) and GFP to mark infected neurons. The truncated TrkB isoform lacks the intracellular tyrosine kinase domain required for signaling and results in a dominant-negative decrease in TrkB signaling (Eide et al., 1996; Gonzalez et al., 1999).

Overexpression of truncated TrkB in hippocampal neurons at 7-10 DIV resulted in a significant, approximately eightfold decrease in the number of NMDAR clusters (Fig. 4A,B; Table 1). NMDAR cluster size was also decreased approximately twofold after overexpression of truncated TrkB (Fig. 4C, Table 1). In addition, few if any of the remaining NMDAR clusters were synaptically localized in neurons overexpressing truncated TrkB (Fig. 4D,E; Table 1), and no change was observed in the number of SP-stained presynaptic boutons in these neurons (Fig. $4 D)[5.2 \pm 0.3$ per $20 \mu \mathrm{m}$ dendritic segment (36); $5.0 \pm 0.5$ in uninfected neurons (40); not significantly different; Student's $t$ test]. No changes were observed in NMDAR cluster number or synaptic localization in neighboring uninfected neurons from the same coverslip (Fig. $4 A-C$ ). Infection with control adenoviruses encoding LacZ and GFP or truncated TrkA and GFP did not alter the number or size of NMDAR clusters (Fig. 4A-C; Table 1). Moreover, in neurons overexpressing truncated TrkB, decreases in NMDAR cluster number were partially reversed, and decreases in size were completely reversed, with the addition of exogenous BDNF (Fig. 4B, C; Table 1). That the addition of exogenous BDNF could partially rescue the effects on NMDAR clusters resulting from overexpression of truncated TrkB suggests that dominant-negative downregulation of Trk signaling occurs via scavenging of ligand in addition to heterodimerization with endogenous full-length TrkB. Together, these results show that postsynaptic TrkB signaling is necessary for the maintenance of NMDAR clusters at hippocampal synapses.
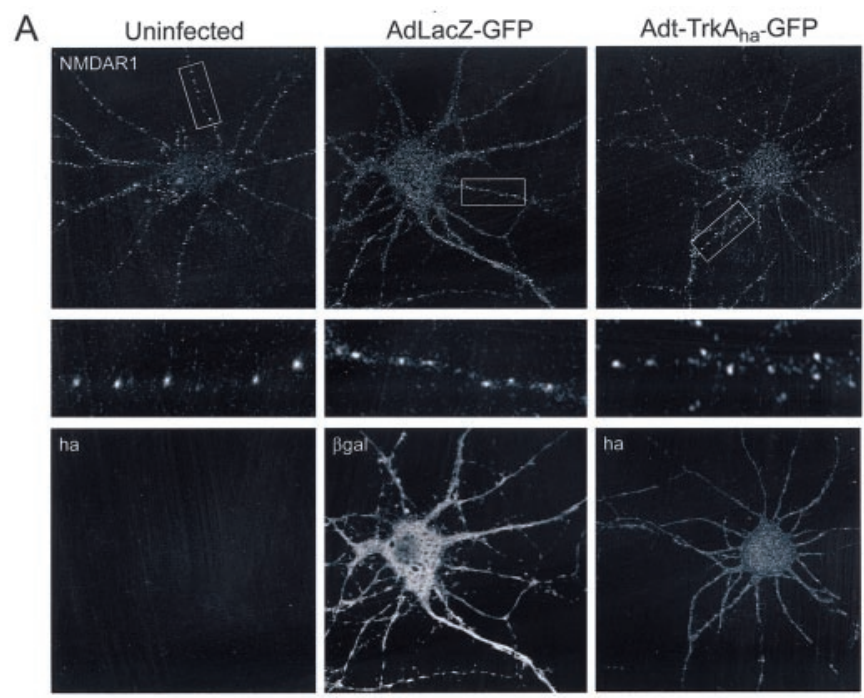

AdTrkB.t $1_{\text {ha }}$-GFP

B
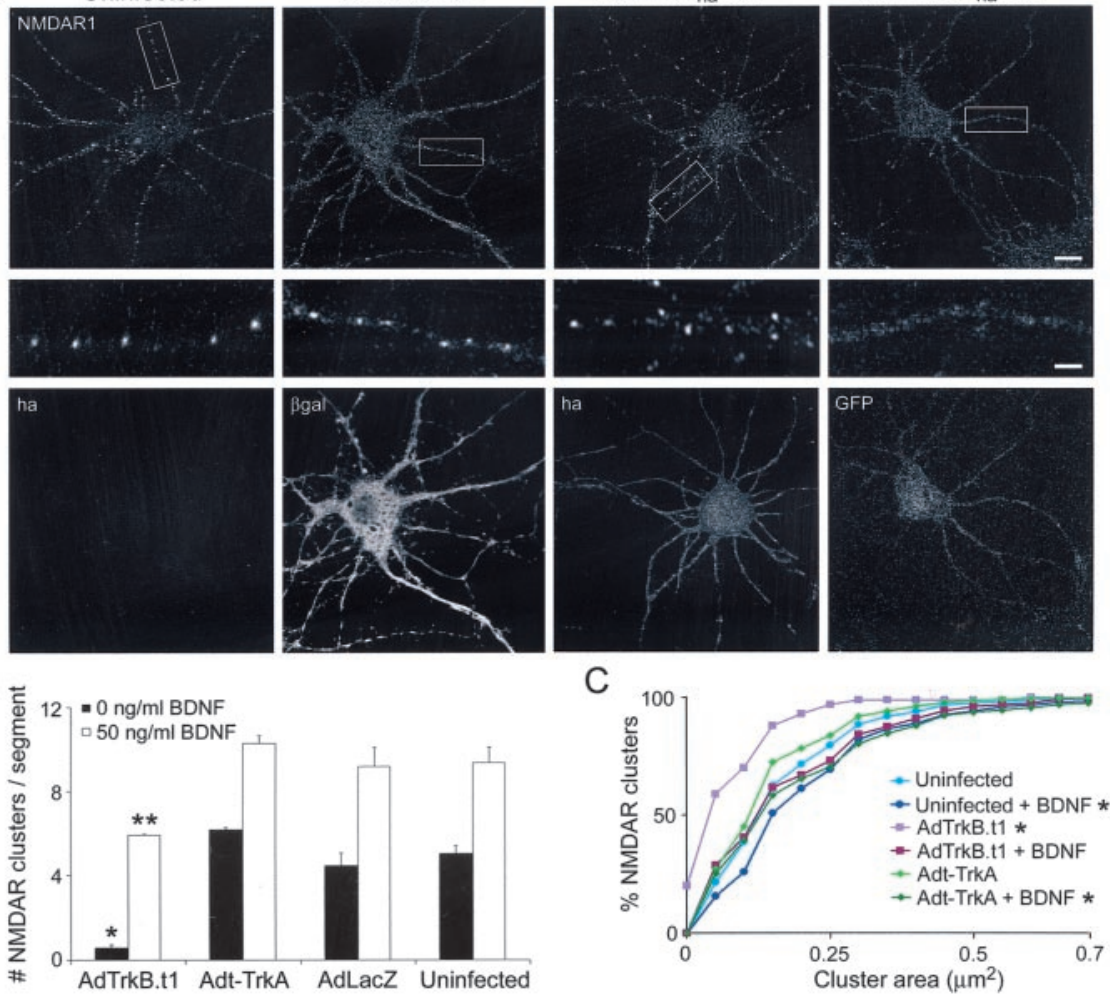

C

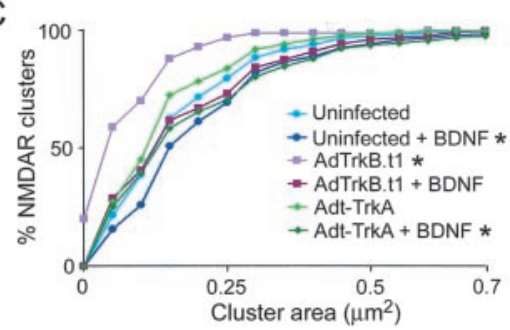

Uninfected
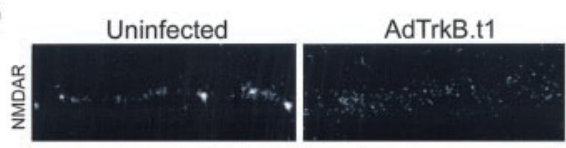

E

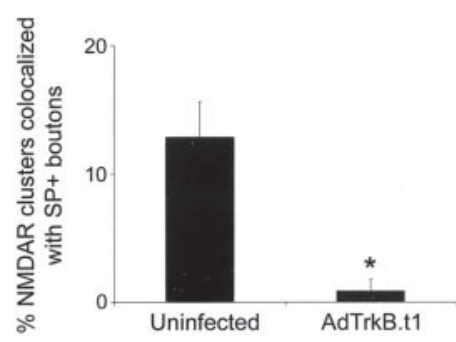

Figure 4. Dominant-negative disruption of TrkB signaling decreases the number, size, and synaptic localization of NMDAR clusters. Hippocampal neurons at 7 DIV were infected with recombinant adenoviruses encoding TrkB.t1 $1_{\text {ha }}, t-$ TrkA $_{\text {ha }}$, LacZ, and GFP. At 10 DIV, neurons were immunostained with antibodies against NR1 (top), or the epitope tag ha or $\beta$-gal (bottom). $A$, Compared with uninfected (left), control infected (left middle, adenovirus encoding LacZ and GFP), and infection with virus encoding truncated TrkA (right middle), overexpression of TrkB.t1 $1_{\text {ha }}$ (right) leads to a decrease in the number of NMDAR clusters. Scale bar, $10 \mu \mathrm{m}$. Areas within white boxes are shown below at higher magnification. Scale bar, $2 \mu \mathrm{m}$. $B$, Quantification of dominant-negative effect of TrkB.t1 ${ }_{\text {ha }}$ overexpression on the number of NMDAR clusters per $20 \mu \mathrm{m}$ dendrite segment in the absence (black bars) and presence (white bars) of $50 \mathrm{ng} / \mathrm{ml}$ BDNF. ${ }^{*}$, Significant decrease compared with no treatment in uninfected neurons; ${ }^{* *}$, significant decrease compared with treatment with $50 \mathrm{ng} / \mathrm{ml}$ BDNF in uninfected neurons (Table 1). The difference between treatment with $50 \mathrm{ng} / \mathrm{mI} \mathrm{BDNF}$ and no treatment was also significant in uninfected, LacZ, and t-TrkA-infected cells ( $p<0.0001$; Student's $t$ test). C, Quantification of effects on NMDAR cluster size. Cumulative histograms of NMDAR cluster size for each treatment are shown. Asterisk indicates significant difference compared with no treatment (Table 1). D, Infection with AdTrkB.t1 (right) leads to a decrease in the synaptic localization of NMDAR clusters compared with uninfected control neurons (left) but has no effect on the number of presynaptic boutons. Top, NMDAR clusters visualized with antibody against NR1. Middle, Presynaptic terminals visualized with an antibody against SP. Bottom, Overlay of NMDAR (red) and SP (green). Scale bar, $2 \mu \mathrm{m}$. E, Quantification of AdTrkB.t1-induced decrease in the synaptic localization of NMDAR clusters compared with uninfected control neurons. Asterisk indicates significant decrease compared with no treatment (Table 1).

\section{TrkB-mediated signaling does not affect expression of NMDARs}

Despite the loss of NMDAR clusters, NMDAR immunoreactivity was not abolished after either BDNF scavenging with TrkB-IgG or overexpression of truncated TrkB (Figs. 3, 4). A consistent, qualitative increase in diffuse membrane staining was observed throughout the somata and dendritic processes of a majority of neurons. To determine whether these qualitative changes in the 


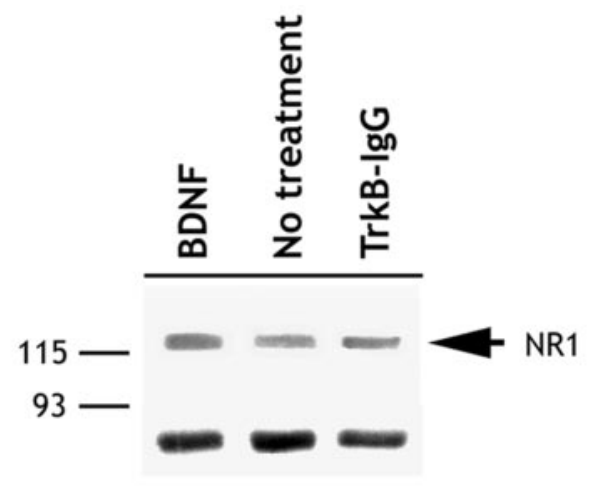

Total cell homogenate

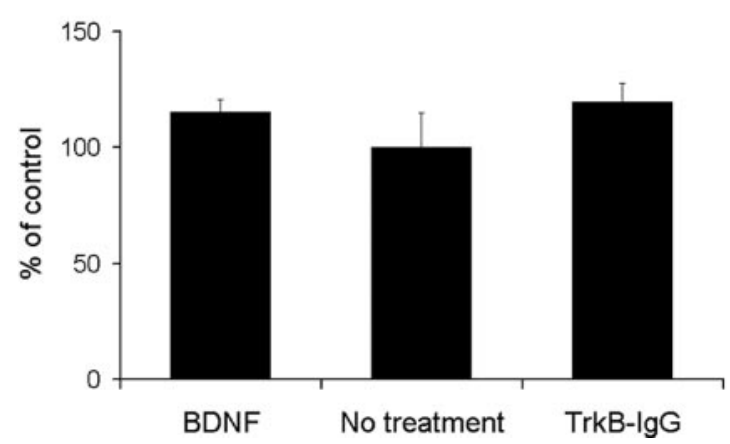

Figure 5. TrkB signaling modulates the clustering of existing NMDARs in hippocampal neurons. Hippocampal neurons at 8 DIV were incubated with $50 \mathrm{ng} / \mathrm{ml} \mathrm{BDNF,} 2 \mu \mathrm{g} / \mathrm{ml} \mathrm{TrkB-lgG}$, or control medium for $48 \mathrm{hr}$. Total cell lysates were harvested at $10 \mathrm{DIV}$. Top, Western blot analysis of total cell homogenate performed using an antibody against NR1. Bottom band is nonspecific and demonstrates loading of each lane. Bottom, Quantification of relative band intensity demonstrates no significant differences across treatments.

pattern of NMDAR immunoreactivity reflected changes in overall NMDAR expression or changes in the membrane distribution of receptors, cultures were treated with BDNF, TrkB-IgG, or control medium for $48 \mathrm{hr}$. After treatment, total cell homogenates were collected, and Western blot analysis was performed. No significant changes were observed in NMDAR expression compared with Kv1.2 expression as an internal standard after treatment with BDNF or TrkB-IgG (Fig. 5). These results suggest that BDNF may promote the assembly of NMDARs into clusters. Conversely, in the absence of BDNF, NMDAR clusters may be disassembled or are removed from the cell surface, but expression levels are not appreciably altered. Because the number of PSD-95 clusters does not change after BDNF scavenging, these results suggest that scavenging BDNF disperses NMDARs from clusters or prevents the accumulation of NMDARs at postsynaptic sites but does not affect the integrity of the postsynaptic density. Together, these data suggest that TrkB signaling is necessary for the maintenance of NMDAR clusters and promotes the assembly of existing NMDARs into clusters.

\section{TrkB signaling modulates the number and synaptic} localization of postsynaptic $\mathrm{GABA}_{\mathrm{A}} \mathrm{R}$ clusters

In the cultures used here, both glutamatergic pyramidal neurons and GABAergic interneurons are present (cf. Rao and Craig, 1997; Brooks-Kayal et al., 1998) and express TrkB receptors. Thus, the role of TrkB-mediated signaling on $\mathrm{GABA}_{\mathrm{A}} \mathrm{R}$ clusters was also examined in cultures treated at 8-10 DIV with BDNF or TrkB-IgG for $48 \mathrm{hr}$. GABA $\mathrm{A}_{\mathrm{A}}$ cluster number, size, and synaptic localization were analyzed by immunostaining and confocal microscopy.

BDNF treatment resulted in an approximately twofold increase in the number of $\mathrm{GABA}_{\mathrm{A}} \mathrm{R}$ clusters compared with untreated control neurons (Fig. 6A, $B$; Table 2) but had no effect on cluster size (Table 2). BDNF treatment also significantly increased the synaptic localization of $\mathrm{GABA}_{\mathrm{A}} \mathrm{R}$ clusters by approximately twofold (Fig. 6A, C; Table 2). This effect was specific to $\mathrm{BDNF}$, because no change in $\mathrm{GABA}_{\mathrm{A}} \mathrm{R}$ cluster number or size was observed with NT-3 or NGF (data not shown). In contrast, reduction of endogenous BDNF by treatment with TrkB-IgG for 48 hr reduced $\mathrm{GABA}_{\mathrm{A}} \mathrm{R}$ cluster number by $\sim 25 \%$, but synaptic localization remained similar to that observed in untreated controls (Table 2). Differences in the immunostaining conditions for NMDAR and $\mathrm{GABA}_{\mathrm{A}} \mathrm{R}$ clusters limited our analysis to examination of these receptors in parallel. However, treatment with BDNF or TrkB-IgG affected NMDAR and $\mathrm{GABA}_{\mathrm{A}} \mathrm{R}$ clusters in the majority $(>75 \%)$ of pyramidal neurons, suggesting that the population of cells affected must be the same or mostly overlapping. Together, these results show that TrkB modulates postsynaptic $\mathrm{GABA}_{\mathrm{A}} \mathrm{R}$ cluster number and synaptic localization over a 48 hr time course similar to that observed for modulation of NMDAR clusters.

TrkB-mediated modulation of postsynaptic $\mathrm{GABA}_{\mathrm{A}} \mathrm{R}$ clusters temporally precedes modulation of NMDAR clusters

The data presented above extend previous reports of the effects of BDNF on channel conductance (Rutherford et al., 1997; Kilman et al., 2002) and $\mathrm{GABA}_{\mathrm{A}} \mathrm{R}$ subunit expression (Yamada et al., 2002) by showing that, over a similar time course, BDNF also modulates the number and localization of $\mathrm{GABA}_{\mathrm{A}} \mathrm{R}$ clusters. However, the effects of BDNF on $\mathrm{GABA}_{\mathrm{A}}$ Rs appear to be highly dynamic, because other work suggests that the function and synaptic localization of $\mathrm{GABA}_{\mathrm{A}} \mathrm{R}$ clusters is decreased after shorter BDNF treatments (Brunig et al., 2001). Moreover, the temporal relationship between the effects of BDNF on $\mathrm{GABA}_{\mathrm{A}} \mathrm{R}$ and NMDAR cluster number and synaptic localization is unknown. Therefore, we directly compared the relative timing of the effects of BDNF on $G_{A B A} R$ and NMDAR clusters in hippocampal cultures.

Cultures were treated with BDNF for 24,36 , and $48 \mathrm{hr}$, and $\mathrm{GABA}_{\mathrm{A}} \mathrm{R}$ and NMDAR cluster number and synaptic localization were analyzed by immunostaining and confocal microscopy. Twenty-four hours of BDNF treatment resulted in a $\sim 40 \%$ decrease in the number of $\mathrm{GABA}_{\mathrm{A}} \mathrm{R}$ clusters compared with untreated control neurons (Fig. $6 A, E$ ) but had no effect on cluster size (data not shown). At this time, BDNF treatment did not significantly alter the synaptic localization of $\mathrm{GABA}_{\mathrm{A}} \mathrm{R}$ clusters (Fig. 6A, F).

After $36 \mathrm{hr}$ of BDNF treatment, however, an approximately twofold increase in the number of $\mathrm{GABA}_{\mathrm{A}} \mathrm{R}$ clusters was observed (Fig. 6A,E). At this time, the synaptic localization of $\mathrm{GABA}_{\mathrm{A}} \mathrm{R}$ clusters was also increased by $\sim 2.5$-fold (Fig. $6 A, F$ ). Moreover, the increase in $\mathrm{GABA}_{\mathrm{A}} \mathrm{R}$ cluster number and synaptic localization persisted after $48 \mathrm{hr}$ of BDNF treatment (Fig. 6A-F; Table 2). At all time points examined, these effects were specific to BDNF, because no change in $\mathrm{GABA}_{\mathrm{A}} \mathrm{R}$ cluster number or size was observed with NT-3 or NGF (data not shown).

In contrast, NMDAR cluster number and synaptic localization were not significantly altered after 24-36 hr of BDNF treatment (Fig. $6 D-F$ ) or at earlier time points (see Materials and Methods). The BDNF-mediated increase in NMDAR cluster number and synaptic localization was only observed after $48 \mathrm{hr}$ of treatment (Fig. 6D-F). Together, these results show that TrkB- 
mediated modulation of $\mathrm{GABA}_{\mathrm{A}} \mathrm{R}$ clusters temporally precedes that of NMDAR clusters by $\sim 12 \mathrm{hr}$.

TrkB-mediated modulation of $\mathrm{GABA}_{\mathrm{A}} \mathrm{R}$ and NMDAR clusters is

activity dependent

In mature networks with high levels of spontaneous activity, BDNF and TrkB signaling can reverse the effects of action potential blockade with TTX on synaptic structure and function (Rutherford et al., 1997, 1998). However, in the less mature cultures studied here, the relationship between activity and BDNF and TrkB signaling on $\mathrm{GABA}_{\mathrm{A}} \mathrm{R}$ and NMDAR cluster number and synaptic localization has not been examined. Therefore, we asked first what the level of spontaneous activity was in cultures at $8-11$ DIV and, second, whether activity was required for TrkB-mediated effects on $\mathrm{GABA}_{\mathrm{A}} \mathrm{R}$ and NMDAR cluster number and synaptic localization.

Cell-attached patch-clamp recordings from pyramidal neurons revealed low levels of spontaneous activity at 8-11 DIV. Some neurons fired spontaneous action potentials at an average frequency of $\sim 0.17 \mathrm{~Hz}(n=15$ of 39 neurons) (Fig. 7A). Other neurons showed lower levels of spontaneous action potential activity. However, whole-cell recordings showed that action potentials could be elicited with current injection and reversibly blocked by TTX $(n=4)$ (Fig. 7B). Whole-cell patch-clamp recordings showed that synaptic activity was infrequent at $8-11$ DIV. In $20 \%$ of neurons, spontaneous IPSCs were observed at a frequency of $\sim 0.02 \mathrm{~Hz}$ but were absent in the majority of neurons examined $(n=15)$ (Fig. 7C). Focal application of GABA elicited currents that were reversibly blocked by the $\mathrm{GABA}_{\mathrm{A}} \mathrm{R}$ antagonist bicuculline $(n=5)$ (Fig. $7 D)$. Few spontaneous EPSCs were observed $(n=13)$; however, in the presence of $10 \mu \mathrm{M} \mathrm{CNQX}$, focal application of glutamate elicited NMDAR-mediated currents that were attenuated with APV (data not shown). Together, these data demonstrate that whereas $\mathrm{GABA}_{\mathrm{A}}$ and NMDA receptors are functional in pyramidal neurons at 8-11 DIV, spontaneous synaptic activity is low, which is consistent with infrequent action potential activity and the low proportion of synaptically localized receptor clusters observed at this stage (compare Fig. 6A).

We next determined whether the effects of TrkB on NMDAR and $G_{A B A} R$ clusters required the low levels of spontaneous action potential activity described above by treating neurons for $48 \mathrm{hr}$ with BDNF and 0.5-2.0 $\mu \mathrm{M}$ TTX. In neurons treated with TTX alone, NMDAR cluster number and size were not significantly different compared with untreated neurons (Fig.

A

B

D
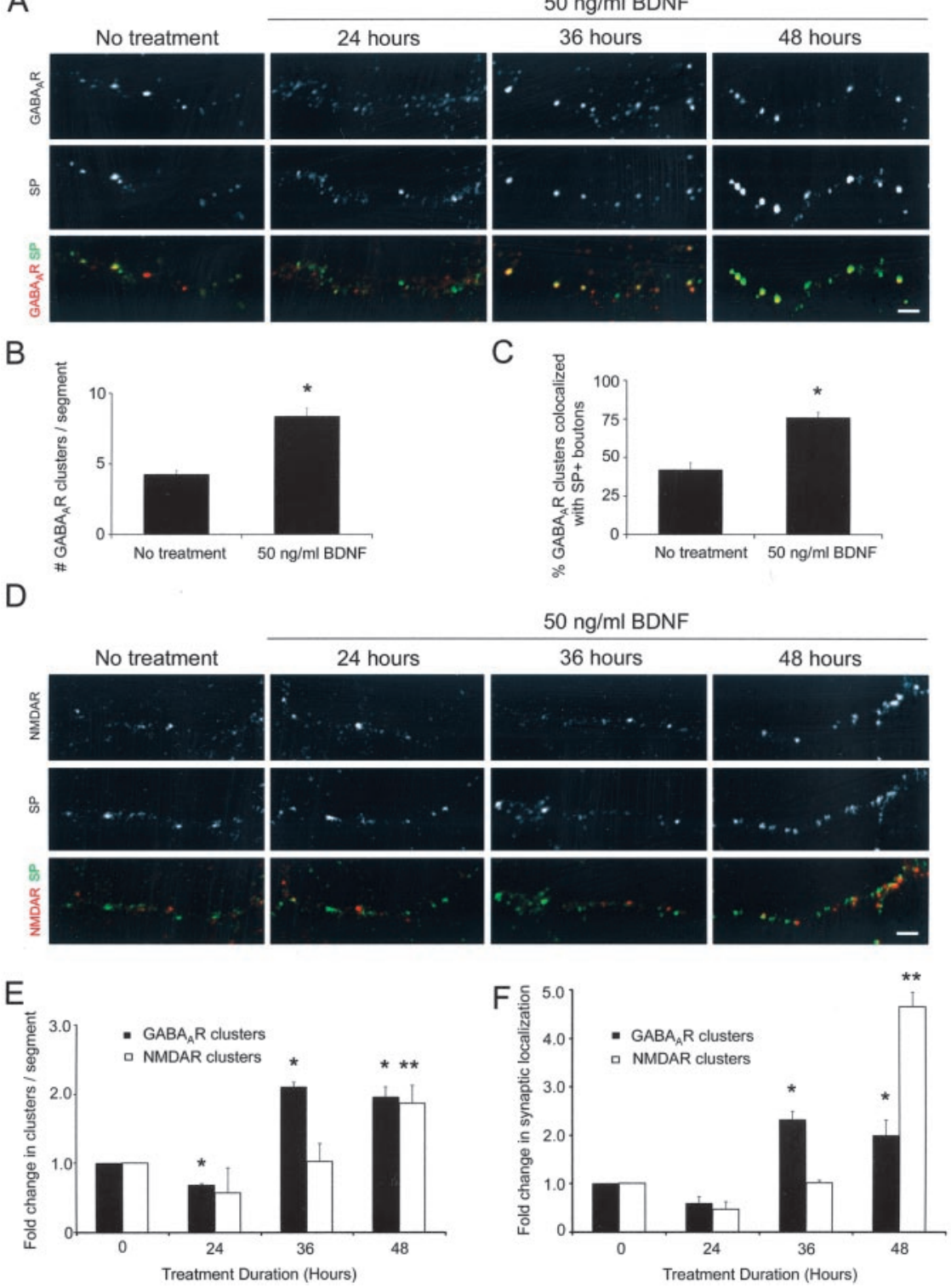

Figure 6. TrkB-mediated modulation of postsynaptic $G_{A B A} R$ cluster number and synaptic localization precedes modulation of NMDAR clusters. Hippocampal neurons at 8 DIV were treated with $50 \mathrm{ng} / \mathrm{ml} \mathrm{BDNF}$ for $24-48 \mathrm{hr}$ and were analyzed after immunostaining at 9 or 10 DIV. $A$, Time course of the effects of BDNF on ABAA $_{A} R$ clusters. Treatment with BDNF for $36 \mathrm{hr}$ (middle right) and $48 \mathrm{hr}$ (right) increases the number of $G A B A_{A} R$ clusters compared with untreated neurons (left). Top, GABA $R$ clusters visualized with antibody against $G A B A_{A} \beta 2 / 3$ subunits. Middle, Presynaptic terminals visualized with an antibody against $S P$. Bottom, 0 verlay of $G A B A_{A} R$ (red) and SP (green). Scale bar, $2 \mu \mathrm{m}$. B, Quantification of $\mathrm{GABA}_{\mathrm{A}} \mathrm{R}$ cluster number per $20 \mu \mathrm{m}$ dendrite segment after $48 \mathrm{hr}$ of BDNF treatment. A significant increase in $G A B A_{A}$ R number was observed compared with no treatment (Table 2). C, Quantification of the proportion of synaptically localized GABAR clusters after $48 \mathrm{hr}$ of BDNF treatment and no treatment. Asterisk indicates significant increase compared with no treatment (Table 2). D, Time course of the effects of BDNF on NMDAR clusters. An increase in NMDAR clusters is observed only after $48 \mathrm{hr}$ (bottom right). Top, NMDAR clusters visualized with antibody against NR1. Middle, Presynaptic terminals visualized with an antibody against SP. Bottom, Overlay of NMDAR (red) and SP (green). Scale bar, $2 \mu \mathrm{m}$. E, Quantification of the fold change in $G A B A_{A} R$ (blackbars) orNMDAR (white bars) clusters per $20 \mu$ m dendrite segment in BDNF-treated compared with untreated neurons at 24,36 , and $48 \mathrm{hr}$. Each bar represents the ratio of the number of clusters per segment in BDNF-treated neurons compared with untreated controls at the time point indicated. Asterisks ( $\left.{ }^{*}, \mathrm{GABA}_{\mathrm{A}} \mathrm{Rs} ;{ }^{*}{ }^{*}, \mathrm{NMDARs}\right)$ indicate significant change from a ratio of 1 observed at $0 \mathrm{hr}$ of treatment. $F_{\text {, }}$ Quantification of the fold change in the proportion of synaptically localized $G A B A_{A} R$ (black bars) and NMDAR (white bars) clusters after BDNF for 24, 36, and $48 \mathrm{hr}$. Each point represents the ratio of the percentage of synaptically localized clusters in BDNF-treated neurons compared with untreated controls at the time point indicated. Asterisks $\left({ }^{*}, \mathrm{GABA}_{\mathrm{A}} \mathrm{Rs} ;{ }^{* *}, \mathrm{NMDARs}\right)$ indicate significant change from a ratio of 1 observed at 0 hr of treatment.

$8 C$, Table 1). However, the synaptic localization of NMDARs was significantly increased in TTX-treated compared with untreated neurons, to a level similar to that observed with BDNF plus TTX or BDNF treatment alone (Fig. $8 A, C, D$; Table 1). Consistent with 
Table 2. TrkB modulation of GABAR cluster number, size, and synaptic localization

\begin{tabular}{llll}
\hline Treatment & GABAR cluster number & GABAR cluster size & GABAR synaptic localization \\
\hline None & $4.3 \pm 0.3(40)$ & $0.17 \pm 0.02$ & $41.9 \pm 4.8$ \\
$50 \mathrm{ng} / \mathrm{ml} \mathrm{BDNF}$ & $8.4 \pm 0.6(38)^{\mathrm{a}}$ & $0.18 \pm 0.02$ & $76 \pm 3.3^{\mathrm{a}}$ \\
$2 \mu \mathrm{g} / \mathrm{ml} \mathrm{TrkB-IgG}$ & $3.0 \pm 0.3(35)^{\mathrm{a}}$ & $0.14 \pm 0.01$ & $31.1 \pm 3.5$ \\
BDNF plus 2 $\mu \mathrm{M}$ TTX & $1.6 \pm 0.3(35)^{\mathrm{a}, \mathrm{b}}$ & $0.13 \pm 0.02$ & $34.6 \pm 5.0^{\mathrm{b}}$ \\
$2 \mu \mathrm{M}$ TTX & $1.9 \pm 0.19(35)^{\mathrm{a}, \mathrm{b}}$ & $0.13 \pm 0.02$ & $28.5 \pm 4.2^{\mathrm{b}}$ \\
\hline
\end{tabular}

Values are shown as mean \pm SEM (number of cells from 3-6 separate experiments). Cluster number was compared using Kruskal-Wallis ANOVA followed by Dunn's pairwise multiple comparison test. Distributions of cluster area were compared using a Kolmolgorov-Smirnov two-sample test, and synaptic localization values were compared using a $t$ test.

${ }^{\text {a }}$ Significantly different from no treatment; $p<0.001$.

bSignificantly different from $50 \mathrm{ng} / \mathrm{ml} \mathrm{BDNF} ; p<0.001$.

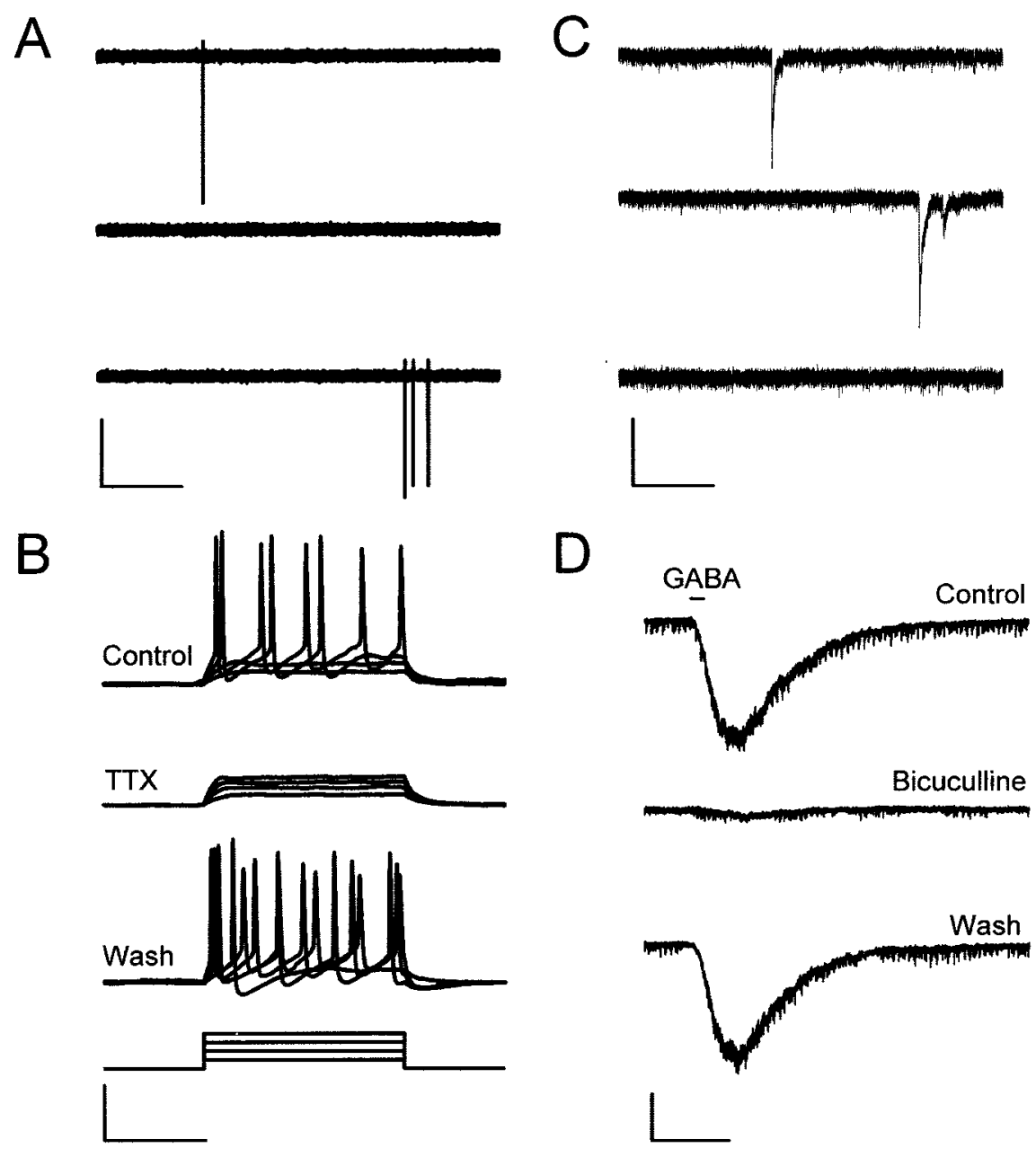

Figure 7. Low levels of spontaneous activity are present during the first week in vitro. Patch-clamp recordings were performed on hippocampal neurons at 8-11 DIV to examine spontaneous and evoked activity. $A$, Representative traces from a neuron in cell-attached voltage-clamp mode. Spontaneous action currents were observed at a low frequency. Calibration: $20 \mathrm{pA}, 1 \mathrm{sec}$. B, Depolarizing current steps (20 pA) elicited action potentials (top) that were abolished by the $\mathrm{Na}^{+}$channel blocker TTX $(1 \mu \mathrm{m}$; middle) and subsequently recovered after washout (bottom). Calibration: $40 \mathrm{mV}, 100 \mathrm{msec}$. C, Representative recordings from three neurons in whole-cell voltage-clamp mode. Spontaneous IPSCs were observed at a low frequency in some neurons (top, middle) and were not observed in the majority of neurons (bottom). Calibration: $40 \mathrm{pA}, 1 \mathrm{sec}$. D, Focal application of $5 \mu \mathrm{m} \mathrm{GABA}$ elicited $\mathrm{GABA}_{\mathrm{A}}$ receptor-mediated currents (top) that were blocked by $50 \mu \mathrm{m}$ bicuculline (middle) and recovered after washout (bottom). Calibration: 200 pA, 2 sec.

previous reports of the effects of action potential blockade in 3-4-week-old hippocampal cultures (Rao and Craig, 1997), this result shows that blockade of even infrequent activity over a $48 \mathrm{hr}$ period can increase NMDAR clusters localized to synapses. Moreover, action potential blockade did not prevent the BDNFinduced increase in NMDAR cluster number, size, and synaptic localization. Together, these results show that action potential block- ade can substitute for the effects of BDNF, at least with respect to the synaptic localization of NMDAR clusters, and suggests that action potential activity and BDNF modulate NMDAR clusters via a common mechanism.

To evaluate the role of NMDAR activity, neurons were treated with $50 \mu \mathrm{m} \mathrm{APV}$ with or without BDNF. APV alone induced an increase in NMDAR cluster number and synaptic localization compared with untreated controls (Table 1). Moreover, like TTX, APV did not block the BDNF-mediated increase in NMDAR cluster number and synaptic localization (Table 1). AMPAR blockade with $10 \mu \mathrm{M}$ CNQX had no effect on NMDAR clusters, nor did it prevent the BDNF-induced increase in NMDAR clusters (Table 1). Consistent with previous reports (Rao and Craig, 1997), these data show that, like action potential blockade, NMDAR blockade, but not AMPAR blockade, can mimic the effects of BDNF on NMDAR cluster number and synaptic localization.

In contrast, in neurons treated with TTX alone, $\mathrm{GABA}_{\mathrm{A}} \mathrm{R}$ cluster number was reduced compared with that observed in untreated neurons (Fig. 8C; Table 2), and the proportion of synaptically localized clusters was unaffected (Fig. 8D, Table 2). Synaptic $\mathrm{GABA}_{\mathrm{A}} \mathrm{R}$ clusters were significantly reduced in neurons treated with BDNF plus TTX compared with neurons treated with BDNF alone (Fig. 8B,C,D; Table 2). These results indicate that TrkBmediated effects on $\mathrm{GABA}_{\mathrm{A}} \mathrm{R}$ clusters are blocked when action potential activity is abolished by TTX.

The results presented thus far show that action potential blockade prevents the effects of BDNF on $\mathrm{GABA}_{\mathrm{A}} \mathrm{R}$ clusters but can mimic the effects of BDNF on NMDAR clusters. One hypothesis that is consistent with these data is that reducing neuronal excitability, either by action potential blockade or by increasing inhibitory input via the BDNF-mediated increase in synaptically localized $\mathrm{GABA}_{\mathrm{A}} \mathrm{R}$ clusters, leads to a subsequent and perhaps compensatory increase in NMDAR clusters. Assuming that GABA is inhibitory at this age, this hypothesis raises two predictions. First, blockade of $\mathrm{GABA}_{\mathrm{A}} \mathrm{R}$ activity would prevent 
the BDNF-mediated increase in NMDAR clusters. Second, activation of $\mathrm{GABA}_{\mathrm{A}} \mathrm{Rs}$ would maintain NMDAR clusters when BDNF is scavenged. These predictions were tested and are described below.

\section{TrkB-mediated modulation of NMDAR} clusters requires $\mathrm{GABA}_{\mathrm{A}} \mathrm{R}$ activity As a first step to evaluate these predictions, perforated-patch recordings were used to determine whether GABA is excitatory or inhibitory at 8-11 DIV (Rivera et al., 1999; Ganguly et al., 2001; Aguado et al., 2003; Wardle and Poo, 2003). In contrast to the $\mathrm{GABA}_{\mathrm{A}} \mathrm{R}$ reversal potential observed at 4 $\operatorname{DIV}(-45.0 \pm 2.5 \mathrm{mV} ; n=6)$, the reversal potential was $\sim 25 \mathrm{mV}$ more hyperpolarized at $8-11 \mathrm{DIV}(-69.4 \pm 3.8 \mathrm{mV} ; n=8)$ (Fig. 9A), near the resting membrane potential. These data suggest that the effects of GABA become inhibitory by the second week of maturation in vitro, consistent with previous work (Vicario-Abejon et al., 1998; Bolton et al., 2000; Ganguly et al., 2001; Wardle and Poo, 2003).

To determine whether $\mathrm{GABA}_{\mathrm{A}} \mathrm{R}$ blockade prevents the BDNF-mediated increase in NMDAR clusters, hippocampal neurons were treated for $48 \mathrm{hr}$ with BDNF while inhibitory synaptic transmission was blocked with $0.5-50 \mu \mathrm{M}$ bicuculline (Fig. 9B-D) (cf. Turrigiano et al., 1998; Marty et al., 2000). When inhibitory synaptic transmission was blocked with $50 \mu \mathrm{M}$ bicuculline, the BDNF-mediated increases in NMDAR cluster number, size, and synaptic localization were abolished. NMDAR cluster density and distribution were similar to that observed in untreated neurons (Fig. 9B-D; Table 1). Treatment with bicuculline alone did not affect NMDAR cluster number, size, and synaptic localization compared with untreated control neurons (Fig. 9C,D; Table 1). These results demonstrate that the BDNF-mediated upregulation in NMDAR clusters requires activation of postsynaptic $\mathrm{GABA}_{\mathrm{A}} \mathrm{Rs}$ and inhibitory synaptic transmission.

To determine whether activation of $\mathrm{GABA}_{\mathrm{A}} \mathrm{Rs}$ maintains NMDAR clusters when BDNF is scavenged, hippocampal neurons were treated for $48 \mathrm{hr}$ with $2 \mu \mathrm{g} / \mathrm{ml}$ TrkB-IgG and $100 \mu \mathrm{M}$ to $10 \mathrm{~mm}$ of GABA. Treatment with exogenous GABA prevented the decrease in NMDAR clusters observed after treatment with TrkB-IgG alone. The number of NMDAR clusters was significantly greater in neurons treated with TrkB-IgG plus $10 \mathrm{~mm}$ GABA than in neurons treated with TrkB-IgG alone (Fig. 9E, F; Table 1). Moreover, treatment with TrkB-IgG plus GABA also prevented the decrease in cluster size and synaptic localization observed with TrkB-IgG treatment alone (Fig. 9G, Table 1). No significant changes in NMDAR cluster number, size, and synaptic localization were observed after treatment with GABA alone (Fig. 9F, G; Table 1). These results show that $\mathrm{GABA}_{\mathrm{A}} \mathrm{R}$ activation is sufficient to maintain NMDAR cluster number and synaptic localization in the absence of BDNF and TrkBmediated signaling.

\section{Discussion}

We show that TrkB signaling modulates the number and synaptic localization of neurotransmitter receptor clusters and other postsynaptic proteins during the formation and maturation of hippocampal synapses in vitro. Activation of TrkB signaling by BDNF led to an increase in the number and synaptic localization of NMDAR and $\mathrm{GABA}_{\mathrm{A}} \mathrm{R}$ clusters. Conversely, downregulation of TrkB signaling by scavenging of endogenous BDNF using TrkB-IgG or by overexpression of a dominant-negative truncated TrkB showed that postsynaptic TrkB signaling is necessary for maintaining NMDAR and $\mathrm{GABA}_{\mathrm{A}} \mathrm{R}$ clusters at synapses. Moreover, BDNF effects on $\mathrm{GABA}_{\mathrm{A}} \mathrm{R}$ clusters temporally preceded those on NMDAR clusters by $12 \mathrm{hr}$. The relationship between activity and BDNF and TrkB signaling on $G_{A B A} R$ and NMDAR clusters was examined by blocking action potential activity with TTX or glutamate receptors with APV or CNQX. Activity blockade had no effect on the BDNF-mediated increase in NMDAR clusters. However, activity blockade alone increased synaptically localized NMDAR clusters, mimicking the effects of BDNF. Although spontaneous activity was observed to be infrequent at 8-11 DIV, activity plays an important role in the localization of NMDAR clusters to synapses.

These data suggest that BDNF increases $\mathrm{GABA}_{\mathrm{A}} \mathrm{R}$ clusters localized to synapses and that reduced neuronal excitability leads to a compensatory increase in NMDAR clusters. Consistent with this hypothesis, blocking $\mathrm{GABA}_{\mathrm{A}} \mathrm{R}$ activity prevented the BDNFmediated increase in NMDAR clusters. Conversely, activation of $\mathrm{GABA}_{\mathrm{A}} \mathrm{Rs}$ led to the maintenance of NMDAR clusters when BDNF was scavenged. Together, these results show that postsynaptic TrkB signaling modulates $\mathrm{GABA}_{\mathrm{A}} \mathrm{R}$ clusters at inhibitory synapses, and that $\mathrm{GABA}_{\mathrm{A}} \mathrm{R}$ activity is required for the formation and maintenance of NMDAR clusters at glutamatergic synapses. Thus, TrkB-mediated signaling may be part of a homeostatic 
A

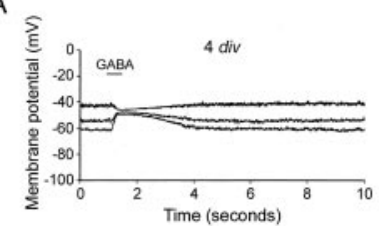

B

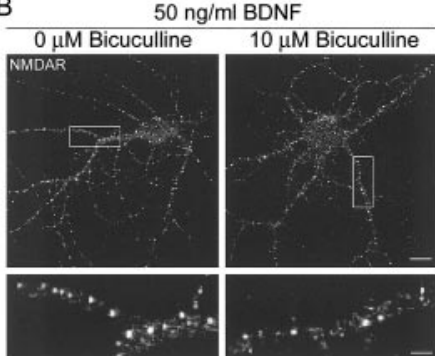

$\mathrm{E}$

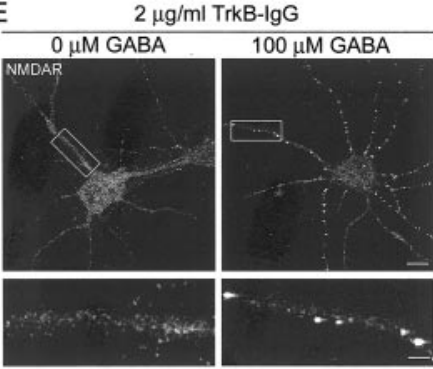

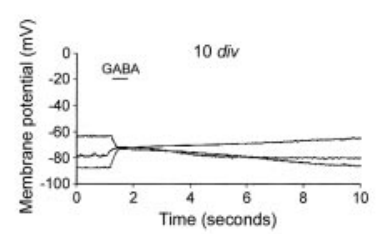

C

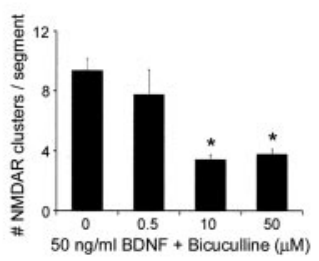

$\mathrm{F}$

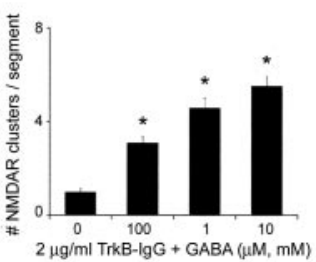

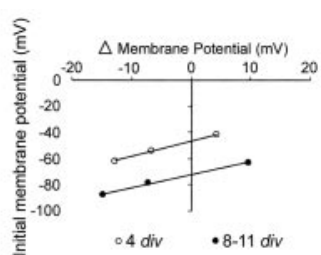

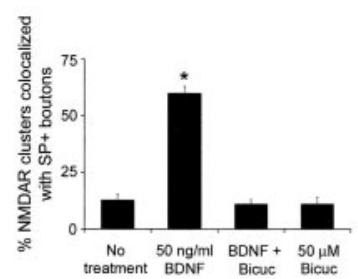

G

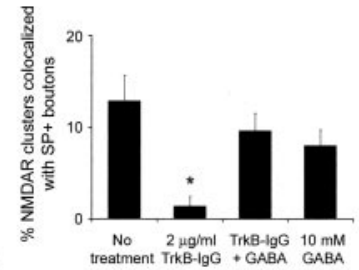

Figure 9. TrkB-mediated modulation of NMDAR clusters requires activity of $G A B A_{A}$ receptors. $A$, Perforated-patch recordings from pyramidal neurons were performed to determine the GABA reversal potential at 4 DIV (left) and 8-11 DIV (middle). The GABA reversal potential decreased from $-45.0 \pm 2.5 \mathrm{mV}$ at $4 \mathrm{DIV}$ to $-69.4 \pm 3.8 \mathrm{mV}$ by the end of the first week in vitro (right). $B$, Hippocampal neurons at 8 DIV were treated with $50 \mathrm{ng} / \mathrm{ml} \mathrm{BDNF}$ and $0-50 \mu \mathrm{m}$ bicuculline, a GABA $A_{A}$ receptor antagonist, for 48 $\mathrm{hr}$ and were analyzed after immunostaining at 10 DIV with an antibody against NR1 and SP. Treatment with BDNF plus $10 \mu \mathrm{m}$ bicuculline led to a decrease in NMDAR cluster number compared with neurons treated with BDNF alone. Scale bar, $10 \mu \mathrm{m}$. Areas within white boxes are shown below at higher magnification. Scale bar, $2 \mu \mathrm{m}$. C, Quantification of BDNF plus bicuculline effects on NMDAR clusters per $20 \mu \mathrm{m}$ dendrite segment. Asterisk indicates significant decrease compared with BDNF only (Table 1).D, Quantification of BDNF plus bicuculline decrease in the synaptic localization of NMDAR clusters compared with neurons treated with BDNF or bicuculline alone. Asterisk indicates significant increase compared with no treatment (Table 1). Synaptic localization after treatment with BDNF plus bicuculline and bicuculline alone was significantly decreased compared with BDNF alone and was not significantly different from no treatment (Table 1).E, Hippocampal neurons at 8 DIV were treated with $2 \mu \mathrm{g} / \mathrm{ml}$ TrkB-lgG and 0-10 $\mathrm{mm}$ GABA for $48 \mathrm{hr}$ and were analyzed after immunostaining at $10 \mathrm{DIV}$ with an antibody against NR1 and SP. Treatment with TrkB-lgG plus $100 \mu \mathrm{M}$ GABA led to an increase in NMDAR cluster number compared with neurons treated with TrkB-lgG alone. Scale bar, $10 \mu \mathrm{m}$. Areas within white boxes are shown below at higher magnification. Scale bar, $2 \mu \mathrm{m}$. F, Quantification of TrkB-IgG plus GABA effects on NMDAR clusters per $20 \mu \mathrm{m}$ dendrite segment. Asterisk indicates significant increase compared with TrkB-IgG alone (Table 1). G, Quantification of TrkB-Ig G plus GABA induced increase in the synaptic localization of NMDAR clusters compared with neurons treated with TrkB-lgG alone or untreated neurons. Asterisk indicates significant decrease compared with no treatment (Table 1).

mechanism that balances excitatory and inhibitory synaptic activity in developing neural circuits.

\section{Postsynaptic localization of full-length TrkB}

Neurotrophins and Trks are widely expressed in the developing and adult CNS and have been shown to modulate process growth, synaptic transmission, and plasticity (for review, see Schuman, 1999; Cohen-Cory, 2002; McAllister, 2002; Vicario-Abejon et al., 2002). Expression of full-length TrkB in hippocampal and other neurons in vivo has been demonstrated as early as E16, approaching adult levels within the first postnatal week (Cabelli et al., 1996; Yan et al., 1997; Martinez et al., 1998). We report that TrkB is primarily localized within the postsynaptic dendritic arbor of hippocampal neurons during maturation in vitro. TrkB was localized to neurons with pyramidal morphology as well as to $\mathrm{GAD}+$ interneurons. We previously showed that both full-

length and truncated TrkB are localized in the postsynaptic muscle fiber membrane at neuromuscular synapses in and around AChR clusters (Gonzalez et al., 1999). In neurons, in vitro as well as in vivo, TrkB is not exclusively localized to hippocampal and other synapses. In hippocampal neuronal cultures immunostained under nonpermeabilizing conditions, some clusters of TrkB were observed at or near presynaptic terminals but were more generally localized extrasynaptically. This pattern of distribution suggests that TrkB may be dynamically trafficked from extrasynaptic to synaptic regions. Alternatively, there may be functional roles for synaptic as well as extrasynaptic TrkB activation. These possibilities remain to be explored in future work.

\section{Postsynaptic TrkB signaling modulates NMDAR and $\mathrm{GABA}_{\mathrm{A}} \mathrm{R}$ clusters at hippocampal synapses}

Postsynaptic target-derived neurotrophin binding to presynaptic Trk receptors had been widely considered to be the dominant mechanism for neurotrophin signaling (DiStefano et al., 1992; Bhattacharyya et al., 1997; Mohrmann et al., 1999; Watson et al., 2001). However, over the last several years, work has demonstrated functional roles for presynaptic neurotrophin release and activation of postsynaptic Trk receptors. Postsynaptic TrkB signaling has been shown to modulate postsynaptic neurotransmitter receptor function at both excitatory and inhibitory synapses (Rutherford et al., 1997, 1998; Bolton et al., 2000; Watt et al., 2000; Brunig et al., 2001; Henneberger et al., 2002; Kilman et al., 2002), to induce neuronal depolarization in postsynaptic neurons (Kafitz et al., 1999; Blum et al., 2002), and to induce LTP at hippocampal synapses (Kovalchuk et al., 2002). The anterograde trafficking of fluorescently tagged BDNF has been documented at hippocampal synapses during development in vitro (Kohara et al., 2001). That TrkB is expressed by both pyramidal neurons and interneurons, and that pyramidal neurons release BDNF in an activity-dependent manner (Kohara et al., 2001), argues that BDNF signaling may be anterograde, retrograde, and perhaps also have an autocrine component. At neuromuscular synapses, we previously showed that postsynaptic TrkB signaling is necessary for the maintenance of AChR clusters (Gonzalez et al., 1999). The results presented here extend this work to neuron-neuron synapses by demonstrating that TrkB signaling modulates $\mathrm{GABA}_{\mathrm{A}} \mathrm{R}$ clusters at inhibitory synapses and NMDAR clusters at glutamatergic synapses in part via a postsynaptic mechanism.

The time course of the TrkB-mediated effects reported here was on the order of 36-48 hr, and little effect was observed at shorter times. Previous work has shown that initial NMDAR cluster formation in cortical and hippocampal neurons at short 
times in vitro (1-3 DIV) is mediated by rapid effects of EphB receptor activation and is not dramatically affected by TrkB activation (Dalva et al., 2000). However, several lines of evidence suggest that different effects of postsynaptic TrkB signaling on synaptic structure and function are observed depending on the time course of activation. Postsynaptic TrkB signaling has been shown to induce NMDAR phosphorylation and increase NMDAR-mediated currents in hippocampal neurons within minutes (Levine et al., 1996, 1998; Jarvis et al., 1997). Similarly, BDNF has been shown to rapidly evoke a neurotransmitter-like depolarization of hippocampal neurons via TrkB-mediated activation of the $\mathrm{Na}_{\mathrm{v}} 1.9$ channel (Kafitz et al., 1999; Blum et al., 2002). Over a time course of several hours, TrkB activation leads to a decrease in $\mathrm{GABA}_{\mathrm{A}} \mathrm{R}$ surface expression and a reduction in miniature IPSC (mIPSC) amplitude in hippocampal neurons (Brunig et al., 2001). In contrast, BDNF treatment for 1-2 d results in an increase in mIPSC amplitude (Rutherford et al., 1997; Li et al., 1998; Vicario-Abejon et al., 1998; Seil and DrakeBaumann, 2000). Although, in the work reported here, no effect of TrkB signaling was observed on NMDAR cluster formation over a time scale of minutes to hours, TrkB signaling modulated $\mathrm{GABA}_{\mathrm{A}} \mathrm{R}$ cluster number and synaptic localization over a $36 \mathrm{hr}$ time course and modulated NMDAR clusters with a $\sim 12 \mathrm{hr}$ delay. In contrast, BDNF had no effect on AMPAR cluster number or synaptic localization at this stage in vitro over any time scale examined, but at later times in development, BDNF signaling differentially scales the strength of AMPAR- and $\mathrm{GABA}_{\mathrm{A}} \mathrm{R}$ containing synapses (Rutherford et al., 1997, 1998; Turrigiano et al., 1998; Watt et al., 2000; Kilman et al., 2002). At neuromuscular synapses, TrkB-mediated signaling has little effect on initial AChR cluster formation in vivo (Gonzalez et al., 1999; C. Cisterni, M. Gonzalez, D. Hess, and R. Balice-Gordon, unpublished results) but plays an important role in ongoing AChR cluster maintenance in vivo and in vitro (Gonzalez et al., 1999; Wells et al., 1999). Together, these studies suggest that TrkB-mediated modulation of postsynaptic neurotransmitter receptor clustering may change over time as neural circuits form and mature.

Therefore, it is important to understand not only the directionality of neurotrophin signaling but also the time scale over which this signaling is functionally relevant. The work presented here suggests that one function of prolonged postsynaptic TrkB signaling is to promote the formation and synaptic localization of postsynaptic neurotransmitter receptor clusters over days as part of a developmental mechanism that regulates synaptic input onto individual neurons.

\section{Activity-dependent effects of neurotrophins on excitatory and inhibitory synapses}

During development, neural networks titrate the level of neuronal excitation and inhibition to allow for efficient synaptic transmission, plasticity, and network stability (for review, see Turrigiano and Nelson, 2000). Recent work suggests that neurons homeostatically modulate synapse number, strength, and ion channel expression to compensate for changes in cell excitability (Liu and Tsien, 1995; Rao and Craig, 1997; Rutherford et al., 1997, 1998; Davis and Goodman, 1998; Turrigiano et al., 1998). Such compensatory regulation is believed to involve intercellular signaling, in part dependent on activity that can lead to changes in presynaptic and postsynaptic structure and function. Candidate signals include the neurotrophins, in particular BDNF, which have been shown to have activity-dependent as well as activityindependent effects on synaptic structure, function, and connec- tivity (Schuman, 1999; Cohen-Cory, 2002; McAllister, 2002; Vicario-Abejon et al., 2002).

Together, with other work, our results highlight the relationship between activity and neurotrophin signaling involved in the homeostatic modulation of excitatory and inhibitory synapses. In contrast to mature neural networks, cultures at 8-11 DIV have relatively low levels of spontaneous action potential and synaptic activity. Nonetheless, the pharmacological manipulations reported here support the idea that even low levels of activity over prolonged periods of time play an important role in the localization of $\mathrm{GABA}_{\mathrm{A}} \mathrm{R}$ and NMDAR clusters to synapses. We demonstrate that TrkB-mediated signaling directly modulates $\mathrm{GABA}_{\mathrm{A}} \mathrm{R}$ clusters in an activity-dependent manner and, with a temporal delay, indirectly modulates NMDAR clusters during periods of synaptogenesis in vitro. The direct modulation of $\mathrm{GABA}_{\mathrm{A}} \mathrm{R}$ clusters is consistent with previous work that has shown that prolonged TrkB signaling enhances interneuron maturation, presynaptic GAD expression (Yamada et al., 2002), and increases postsynaptic $\mathrm{GABA}_{\mathrm{A}}$ receptor conductance (Rutherford et al., 1997) and mIPSC amplitude (Li et al., 1998; Vicario-Abejon et al., 1998; Marty et al., 2000; Seil and Drake-Baumann, 2000). The BDNF-mediated increase in NMDAR cluster number and synaptic localization is indirect and requires $\mathrm{GABA}_{\mathrm{A}} \mathrm{R}$ activation but not action potential activity per se. Thus, the direct and indirect effects of TrkB signaling on neurotransmitter receptor clusters may establish a level of excitatory and inhibitory activity that promotes ongoing synapse formation and ultimately shapes circuit function. Understanding the effector mechanisms downstream of TrkB activation that coordinately modulate $\mathrm{GABA}_{\mathrm{A}} \mathrm{R}$ and NMDAR clusters at CNS synapses, or modulate the maintenance of AChR clusters at neuromuscular synapses, will be the focus of future work.

\section{References}

Aguado F, Carmona MA, Pozas E, Aguilo A, Martinez-Guijarro FJ, Alcantara S, Borrell V, Yuste R, Ibanez CF, Soriano E (2003) BDNF regulates spontaneous correlated activity at early developmental stages by increasing synaptogenesis and expression of the $\mathrm{K}+/ \mathrm{Cl}$ - co-transporter $\mathrm{KCC} 2$. Development 130:1267-1280.

Bhattacharyya A, Watson FL, Bradlee TA, Pomeroy SL, Stiles CD, Segal RA (1997) Trk receptors function as rapid retrograde signal carriers in the adult nervous system. J Neurosci 17:7007-7016.

Binder DK, Routbort MJ, Ryan TE, Yancopoulos GD, McNamara JO (1999) Selective inhibition of kindling development by intraventricular administration of TrkB receptor body. J Neurosci 19:1424-1436.

Blum R, Kafitz KW, Konnerth A (2002) Neurotrophin-evoked depolarization requires the sodium channel $\mathrm{Na}(\mathrm{V}) 1.9$. Nature 419:687-693.

Bolton MM, Pittman AJ, Lo DC (2000) Brain-derived neurotrophic factor differentially regulates excitatory and inhibitory synaptic transmission in hippocampal cultures. J Neurosci 20:3221-3232.

Brooks-Kayal AR, Jin H, Price M, Dichter MA (1998) Developmental expression of $\mathrm{GABA}(\mathrm{A})$ receptor subunit $\mathrm{mRNAs}$ in individual hippocampal neurons in vitro and in vivo. J Neurochem 70:1017-1028.

Brunig I, Penschuck S, Berninger B, Benson J, Fritschy JM (2001) BDNF reduces miniature inhibitory postsynaptic currents by rapid downregulation of $\mathrm{GABA}(\mathrm{A})$ receptor surface expression. Eur J Neurosci 13:1320-1328.

Cabelli RJ, Allendoerfer KL, Radeke MJ, Welcher AA, Feinstein SC, Shatz CJ (1996) Changing patterns of expression and subcellular localization of trkB in the developing visual system. J Neurosci 16:7965-7980.

Carmignoto G, Vicini S (1992) Activity-dependent decrease in NMDA receptor responses during development of the visual cortex. Science 258:1007-1011.

Cohen-Cory S (2002) The developing synapse: construction and modulation of synaptic structures and circuits. Science 298:770-776.

Cohen-Cory S, Fraser SE (1995) Effects of brain-derived neurotrophic factor on optic axon branching and remodeling in vivo. Nature 378:192-196. 
Dalva MB, Takasu MA, Lin MZ, Shamah SM, Hu L, Gale NW, Greenberg ME (2000) EphB receptors interact with NMDA receptors and regulate excitatory synapse formation. Cell 103:945-956.

Davis GW, Goodman CS (1998) Genetic analysis of synaptic development and plasticity: homeostatic regulation of synaptic efficacy. Curr Opin Neurobiol 8:149-156.

DiStefano PS, Friedman B, Radziejewski C, Alexander C, Boland P, Schick CM, Lindsay RM, Wiegand SJ (1992) The neurotrophins BDNF, NT-3, and NGF display distinct patterns of retrograde axonal transport in peripheral and central neurons. Neuron 8:983-993.

Du J, Feng L, Yang F, Lu B (2000) Activity- and Ca(2+)-dependent modulation of surface expression of brain-derived neurotrophic factor receptors in hippocampal neurons. J Cell Biol 150:1423-1434.

Eide FF, Vining ER, Eide BL, Zang K, Wang XY, Reichardt LF (1996) Naturally occurring truncated trkB receptors have dominant inhibitory effects on brain-derived neurotrophic factor signaling. J Neurosci 16:3123-3129.

Ganguly K, Schinder AF, Wong ST, Poo M (2001) GABA itself promotes the developmental switch of neuronal GABAergic responses from excitation to inhibition. Cell 105:521-532.

Gonzalez M, Ruggiero FP, Chang Q, Shi YJ, Rich MM, Kraner S, BaliceGordon RJ (1999) Disruption of TrkB-mediated signaling induces disassembly of postsynaptic receptor clusters at neuromuscular junctions. Neuron 24:567-583.

Goslin K, Schreyer DJ, Skene JH, Banker G (1988) Development of neuronal polarity: GAP-43 distinguishes axonal from dendritic growth cones. Nature 336:672-674.

Henneberger C, Juttner R, Rothe T, Grantyn R (2002) Postsynaptic action of BDNF on GABAergic synaptic transmission in the superficial layers of the mouse superior colliculus. J Neurophysiol 88:595-603.

Jarvis CR, Xiong ZG, Plant JR, Churchill D, Lu WY, MacVicar BA, MacDonald JF (1997) Neurotrophin modulation of NMDA receptors in cultured murine and isolated rat neurons. J Neurophysiol 78:2363-2371.

Kafitz KW, Rose CR, Thoenen H, Konnerth A (1999) Neurotrophin-evoked rapid excitation through TrkB receptors. Nature 401:918-921.

Kang H, Schuman EM (1995) Long-lasting neurotrophin-induced enhancement of synaptic transmission in the adult hippocampus. Science 267:1658-1662.

Kang H, Schuman EM (1996) A requirement for local protein synthesis in neurotrophin-induced hippocampal synaptic plasticity. Science 273:1402-1406.

Kang H, Welcher AA, Shelton D, Schuman EM (1997) Neurotrophins and time: different roles for TrkB signaling in hippocampal long-term potentiation. Neuron 19:653-664.

Kilman V, van Rossum MC, Turrigiano GG (2002) Activity deprivation reduces miniature IPSC amplitude by decreasing the number of postsynaptic GABA(A) receptors clustered at neocortical synapses. J Neurosci 22:1328-1337.

Kohara K, Kitamura A, Morishima M, Tsumoto T (2001) Activitydependent transfer of brain-derived neurotrophic factor to postsynaptic neurons. Science 291:2419-2423.

Kovalchuk Y, Hanse E, Kafitz KW, Konnerth A (2002) Postsynaptic induction of BDNF-mediated long-term potentiation. Science 295:1729-1734.

Levine ES, Dreyfus CF, Black IB, Plummer MR (1996) Selective role for trkB neurotrophin receptors in rapid modulation of hippocampal synaptic transmission. Brain Res Mol Brain Res 38:300-303.

Levine ES, Crozier RA, Black IB, Plummer MR (1998) Brain-derived neurotrophic factor modulates hippocampal synaptic transmission by increasing N-methyl-D-aspartic acid receptor activity. Proc Natl Acad Sci USA 95:10235-10259.

Li YX, Zhang Y, Lester HA, Schuman EM, Davidson N (1998) Enhancement of neurotransmitter release induced by brain-derived neurotrophic factor in cultured hippocampal neurons. J Neurosci 18:10231-10240.

Liu G, Tsien RW (1995) Synaptic transmission at single visualized hippocampal boutons. Neuropharmacology 34:1407-1421.

Martinez A, Alcantara S, Borrell V, Del Rio JA, Blasi J, Otal R, Campos N, Boronat A, Barbacid M, Silos-Santiago I, Soriano E (1998) TrkB and TrkC signaling are required for maturation and synaptogenesis of hippocampal connections. J Neurosci 18:7336-7350.
Marty S, Wehrle R, Sotelo C (2000) Neuronal activity and brain-derived neurotrophic factor regulate the density of inhibitory synapses in organotypic slice cultures of postnatal hippocampus. J Neurosci 20:8087-8095.

McAllister AK (2002) Spatially restricted actions of BDNF. Neuron 36:549-550.

McAllister AK, Katz LC, Lo DC (1996) Neurotrophin regulation of cortical dendritic growth requires activity. Neuron 17:1057-1064.

McAllister AK, Katz LC, Lo DC (1997) Opposing roles for endogenous BDNF and NT-3 in regulating cortical dendritic growth. Neuron 18:767-778.

Mohrmann R, Werner M, Hatt H, Gottmann K (1999) Target-specific factors regulate the formation of glutamatergic transmitter release sites in cultured neocortical neurons. J Neurosci 19:10004-10013.

Muragaki Y, Timothy N, Leight S, Hempstead BL, Chao MV, Trojanowski JQ, Lee VM (1995) Expression of Trk receptors in the developing and adult human central and peripheral nervous system. J Comp Neurol 356:387-397.

Rao A, Craig AM (1997) Activity regulates the synaptic localization of the NMDA receptor in hippocampal neurons. Neuron 19:801-812.

Rivera C, Voipio J, Payne JA, Ruusuvuori E, Lahtinen H, Lamsa K, Pirvola U, Saarma M, Kaila K (1999) The K+/Cl- cotransporter KCCS renders GABA hyperpolarizing during neuronal maturation. Nature 397:251-255.

Rutherford LC, DeWan A, Lauer HM, Turrigiano GG (1997) Brain-derived neurotrophic factor mediates the activity-dependent regulation of inhibition in neocortical cultures. J Neurosci 17:4527-4535.

Rutherford LC, Nelson SB, Turrigiano GG (1998) BDNF has opposite effects on the quantal amplitude of pyramidal neuron and interneuron excitatory synapses. Neuron 21:521-530.

Schuman EM (1999) Neurotrophin regulation of synaptic transmission. Curr Opin Neurobiol 9:105-109.

Seil FJ, Drake-Baumann R (2000) TrkB receptor ligands promote activitydependent inhibitory synaptogenesis. J Neurosci 20:5367-5373.

Turrigiano GG, Nelson SB (2000) Hebb and homeostasis in neuronal plasticity. Curr Opin Neurobiol 10:358-364.

Turrigiano GG, Leslie KR, Desai NS, Rutherford LC, Nelson SB (1998) Activity-dependent scaling of quantal amplitude in neocortical neurons. Nature 391:892-896.

Vicario-Abejon C, Collin C, McKay RD, Segal M (1998) Neurotrophins induce formation of functional excitatory and inhibitory synapses between cultured hippocampal neurons. J Neurosci 18:7256-7271.

Vicario-Abejon C, Owens D, McKay R, Segal M (2002) Role of neurotrophins in central synapse formation and stabilization. Nat Rev Neurosci 3:965-974.

Wardle R, Poo M-M (2003) Brain-derived neurotrophic factor modulation of GABAergic synapses by postsynaptic regulation of chloride transport. J Neurosci 23:8722-8732.

Watson FL, Heerssen HM, Bhattacharyya A, Klesse L, Lin MZ, Segal RA (2001) Neurotrophins use the Erk5 pathway to mediate a retrograde survival response. Nat Neurosci 4:981-988.

Watt AJ, van Rossum MC, MacLeod KM, Nelson SB, Turrigiano GG (2000) Activity coregulates quantal AMPA and NMDA currents at neocortical synapses. Neuron 26:659-670.

Wells DG, McKechnie BA, Kelkar S, Fallon JR (1999) Neurotrophins regulate agrin-induced postsynaptic differentiation. Proc Natl Acad Sci USA 96:1112-1117.

Xu B, Gottschalk W, Chow A, Wilson RI, Schnell E, Zang K, Wang D, Nicoll RA, Lu B, Reichardt LF (2000) The role of brain-derived neurotrophic factor receptors in the mature hippocampus: modulation of long-term potentiation through a presynaptic mechanism involving TrkB. J Neurosci 20:6888-6897.

Yamada MK, Nakanishi K, Ohba S, Nakamura T, Ikegaya Y, Nishiyama N, Matsuki N (2002) Brain-derived neurotrophic factor promotes the maturation of GABAergic mechanisms in cultured hippocampal neurons. J Neurosci 22:7580-7585.

Yan Q, Radeke MJ, Matheson CR, Talvenheimo J, Welcher AA, Feinstein SC (1997) Immunocytochemical localization of TrkB in the central nervous system of the adult rat. J Comp Neurol 378:135-157. 